\title{
LAS FALLAS PURIRES Y PICAGRES, Y SU RELACIÓN CON LA SECUENCIA SÍSMICA DE PURISCAL DE 1990
}

\author{
PURIRES AND PICAGRES FAULTS AND ITS RELATIONSHIP \\ WITH THE 1990 PURISCAL SEISMIC SEQUENCE
}

\author{
Walter Montero $^{1 *} \&$ Wilfredo Rojas ${ }^{1,2}$ \\ ${ }^{1}$ Centro de Investigaciones en Ciencias Geológicas (CICG), \\ Universidad de Costa Rica \\ ${ }^{2}$ Escuela Centroamericana de Geología y Red Sismológica Nacional (RSN, \\ UCR-ICE), Universidad de Costa Rica, Apdo. 214-2060, \\ Ciudad Universitaria Rodrigo Facio, Costa Rica \\ *Autor para contacto: wmontero@geologos.or.cr
}

(Recibido: 6/01/2014 ; aceptado: 15/05/2014)

\begin{abstract}
New morphotectonic, structural, and seismological interpretations have allowed us to define the neotectonics of the region located between the northwestern border of the Talamanca cordillera and the southern flanks of Aguacate Mounts, along the central-western sector of the Central Costa Rican Deformed Belt. The principal tectonic structures identified in this study are the Purires, Zapote, Jaris, Bajos de Jorco and Picagres faults. They constitute a set of northwest dextral-slip faults, traversing for more than $45 \mathrm{~km}$ the previous mountains ranges. Transtensive and transpressive structures were identified along these faults. Another recognized structure is the Junquillo fault, a predominantly east-west sinistral fault that lies between the Purires and Picagres faults.

The three stages of the 1990 Puriscal shallow seismic sequence are reviewed in this study and are related with some of the previous faults. The seismic activity began with a seismic swarm that showed a peak of activity between May and June. The swarm showed a migration of activity between the Picagres and Purires faults. A right-lateral surface fault rupture with a length of $400 \mathrm{~m}$, associated with two seismic events occurred on June 8 (00:31 GMT; Md 4.8) and June 9 (00:34 GMT; Md 4.8), breaks a sector of the eastern branch of Charcón transtensive structure of the Picagres fault. The seismic sequence continued with the Barbacoas earthquake of June $30\left(\mathrm{M}_{\mathrm{s}} 5.1\right)$. This earthquake and its aftershocks located until July 11, rupture a $9 \mathrm{~km}$ length segment of the Purires fault. Finally, the Piedras Negras earthquake of December 22, 1990 ( $\mathrm{M}_{\mathrm{s}}$ 5.7) and its aftershocks occurred until December 30, caused a rupture of $11 \mathrm{~km}$ length of the Picagres fault.
\end{abstract}

Keywords: Neotectonics, morphotectonics, structural geology, seismicity, Puriscal shallow seismic sequence of 1990.

RESUMEN: Nuevas interpretaciones morfotectónicas, estructurales y sismológicas han permitido definir la neotectónica de la región comprendida entre el flanco noroeste de la cordillera de Talamanca y el flanco sur de los Montes del Aguacate, dentro del sector central-oeste del Cinturón Deformado del Centro de Costa Rica. Las principales estructuras 
tectónicas reconocidas en este estudio son las fallas Purires, Zapote, Jaris, Bajos de Jorco y Picagres. Las mismas constituyen un conjunto de fallas de rumbo noroeste de desplazamiento predominantemente dextral, las cuales atraviesan por más de $45 \mathrm{~km}$, los sistemas montañosos de la zona de estudio. Estructuras transtensivas y transpresivas asociadas con estas fallas son asimismo descritas. Otra estructura identificada es la falla Junquillo, de rumbo cercano al E-W y movimiento sinestral, la cual se ubica entre las fallas Purires y Picagres.

Los tres estadios principales de la secuencia sísmica superficial de Puriscal de 1990 son revisados en este estudio y son relacionados con algunas de las anteriores fallas. Esta se inició con un enjambre sísmico que alcanzó su pico de actividad entre mayo y junio. El mismo migró entre las fallas Picagres y Purires. Los eventos sísmicos del 8 de junio (00:31 GMT; Md 4,8) y del 9 de junio (00:34 GMT; Md 4,8), originaron una ruptura de falla lateral derecha de 400m de longitud, a lo largo de un segmento del ramal este de la estructura transtensiva de Charcón, asociada con la falla Picagres. La secuencia sísmica continuó con el terremoto de Barbacoas del 30 de junio ( $\mathrm{M}_{\mathrm{s}}$ 5,1). Este temblor y la secuencia de réplicas ocurridas hasta el 11 de julio, originó una ruptura de falla de $9 \mathrm{~km}$ de longitud, a lo largo de la falla Purires. Finalmente, ocurrió el terremoto de Piedras Negras del 22 de diciembre de 1990 (M 5,7). Este sismo y su secuencia de réplicas ocurridas hasta el 30 de diciembre, originaron una ruptura de $11 \mathrm{~km}$ de largo a lo largo la falla Picagres.

Palabras clave: Neotectónica, morfotectónica, geología estructural, sismicidad, secuencia superficial sísmica de Puriscal de 1990.

\section{INTRODUCCION}

Los estudios geodésicos reportados por LaFemina et al. (2009) y Feng et al. (2012) indican que la región central y noroeste de Costa Rica tiene un escape tectónico al noroeste a una tasa de entre 8 a $11 \mathrm{~mm} / \mathrm{año,} \mathrm{el} \mathrm{cual} \mathrm{se} \mathrm{distribuye} \mathrm{en}$ una forma aún no determinada entre un complejo arreglo de fallas activas que existen dentro de esta amplia zona (Fig. 1). Por otro lado, la determinación de las fallas que originan la actividad sísmica en la región central de Costa Rica representa un reto significativo, considerando que en ambientes tropicales, la preservación de las formas del terreno asociadas con la tectónica activa pueden ser bastante limitadas, máxime si las fallas tienen tasas de actividad bajas, como lo indican los datos geodésicos previos. Una zona donde se presenta una gran complejidad neotectónica con varias fallas activas, es la región comprendida entre el flanco sur de los montes del Aguacate y el flanco noroeste de la cordillera de Talamanca (Fig. 1). La misma fue afectada por una secuencia sísmica en el año de 1990 e inicios de 1991, que incluyó un enjambre de temblores entre fines de marzo y mediados de junio, el cual fue seguido por los terremotos de Barbacoas del 30 de junio de $1990\left(M_{\mathrm{s}}\right.$ 5,1) y de Piedras Negras del 22 de diciembre de 1990 $\left(M_{s} 5,7\right)$. Esta sismicidad, que se ha denominado en forma conjunta como la secuencia sísmica de Puriscal, tuvo un considerable impacto social y económico en el sector oeste y suroeste de la zona central de Costa Rica.

A raíz de la secuencia sísmica cortical $(\mathrm{h} \leq$ $20 \mathrm{~km}$ ) de Puriscal de 1990, se hicieron varios estudios acerca de la sismicidad, la sismotectónica y la distribución de daños relacionados con los eventos principales. Destacan los trabajos de Güendel et al. (1990), Barquero et al. (1991b), Rojas \& Barquero (1991), Fernández (1995) y Fernández \& Pacheco (1998). A partir de los mecanismos focales obtenidos a partir de algunos de los anteriores autores, Lewis et al. (2008) obtuvieron una dirección sub-horizontal de alargamiento de dirección ENE-WSW. Asimismo, Quintero \& Güendel (2000) obtuvieron, un esfuerzo máximo $\left(16^{\circ} / 23^{\circ}\right)$ y uno mínimo $\left(276^{\circ} / 20^{\circ}\right)$, ambos subhorizontales. Mientras tanto, López (1999; 2012) obtuvo las direcciones de esfuerzos principales mediante métodos de inversión de esfuerzos. Por ejemplo, para los mecanismos focales reportados por Montero et al. (1991a), López (1999) obtuvo un $\sigma_{1}$ de $23^{\circ} / 00^{\circ}$ y un $\sigma_{3}$ de $293^{\circ} / 12^{\circ}$. Por otro lado, Montero et al. (1990; 1991 a y b), Arias \& Denyer (1991b), Güendel et al. (1995), Fernández (1995) y Fernández \& Pacheco (1998) consideraron diversas fallas como las fuentes de la actividad sísmica superficial en la zona de Puriscal. 


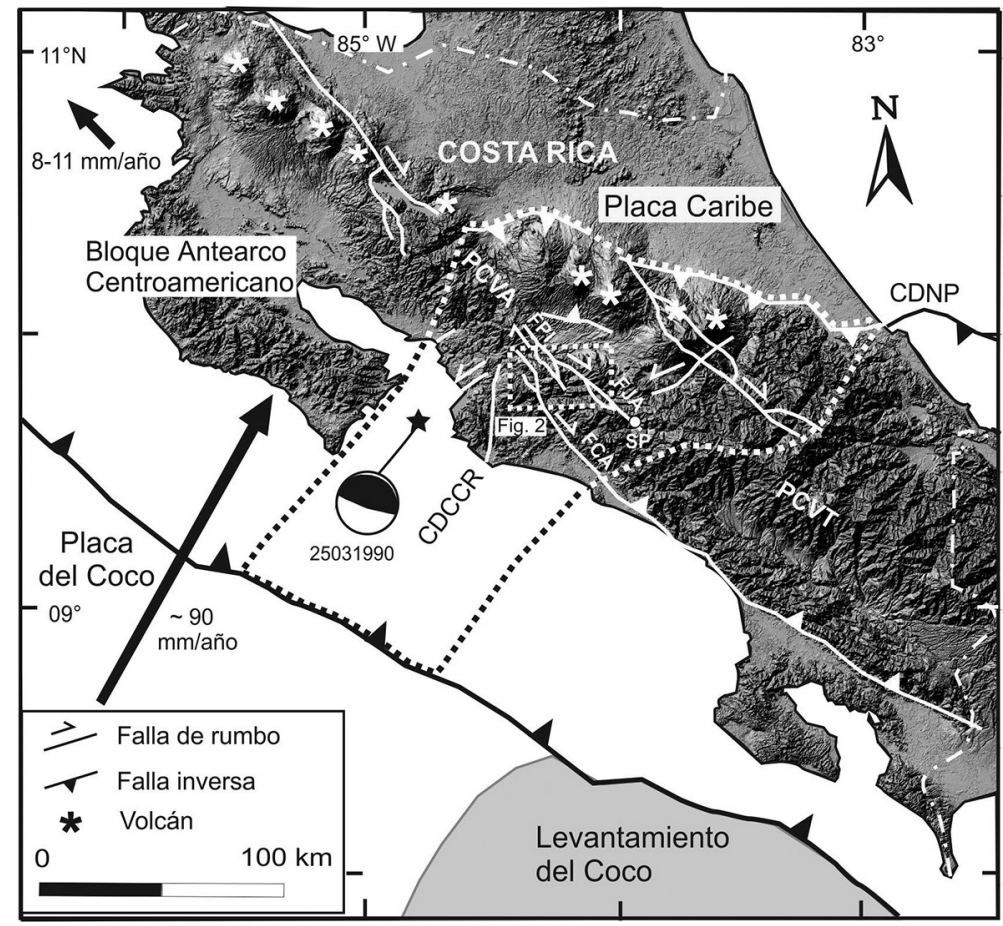

Fig. 1: Marco tectónico. Muestra las placas tectónicas que interactúan en la región de Costa Rica. La flecha rellena en negro muestra la velocidad relativa Coco-Caribe a una escala que es la mitad de la escala de la flecha de la velocidad del Bloque del Antearco Centroamericano, obtenida por Norabuena et al. (2004) y Feng et al. (2012). La zona comprendida dentro de la línea a puntos negra (zona marina) y blanca (zona terrestre) muestra la ubicación del Cinturón Deformado del Centro de Costa Rica (CDCCR), que atraviesa la región central de Costa Rica y que termina al Este en el Cinturón Deformado del Norte de Panamá (CDNP). La estrella negra corresponde con el epicentro del terremoto de la entrada del golfo de Nicoya del 25 de marzo de $1990\left(\mathrm{M}_{\mathrm{s}} 7,1\right)$ y el respectivo mecanismo focal obtenido de Protti et al. (1995). El rectángulo a puntos blancos muestra el área de estudio, que cubre la figura 2. PVCA y PVCT son respectivamente las paleo-cordilleras volcánicas de Aguacate y de Talamanca. FCA, FPI y FJA son respectivamente las fallas Candelaria, Picagres y Jaris. El círculo relleno en blanco indica la ubicación de San Pablo de León Cortés (SP).

Sin embargo, estos estudios muestran importantes discrepancias con respecto a la determinación de las fallas que originaron la secuencia sísmica. Por ejemplo, Montero et al. (1990; 1991 a y b) sugirieron que la actividad sísmica se relacionó con las fallas Picagres, San Antonio, Desamparaditos, Dantas, Víbora y Virilla. Un hecho destacado es que estos autores relacionaron el terremoto de Piedras Negras del 22 de diciembre de 1990 $\left(\mathrm{M}_{\mathrm{s}} 5,7\right)$ con la falla Virilla, una falla sugerida de movimiento sinestral. Arias \& Denyer (1991b) detallaron la geología y las fallas de la zona de Puriscal, definiendo un sistema NW de tipo dextral y otro de rumbo NE, de carácter sinestral. Asimismo, realizaron un análisis estructural entre las fallas, estrías y los mecanismos focales.
Fernández (1995) y Fernández \& Pacheco (1998) sugieren que una parte importante de la actividad sísmica se relacionó con la falla Cortezal, de rumbo NE. Por otro lado, Güendel et al. (1995) relacionaron la sismicidad con sistemas de fallas NE-SW y NW-SE. Un común denominador de las anteriores investigaciones es que no se determinó una clara relación entre la actividad sísmica y las fallas propuestas. Debido a lo anterior, el presente artículo tiene como objetivo principal, reevaluar el sistema de fallas activas de la región comprendida entre el flanco sur de los Montes del Aguacate y el flanco noroeste de la cordillera de Talamanca y definir su relación con la actividad sísmica ocurrida entre fines de marzo de 1990 y principios de 1991. La investigación se realizó a 
partir de una detallada revisión de: 1. Fotografías aéreas de diferentes escalas del Instituto Geográfico Nacional de Costa Rica (IGN). 2. Fotografías aéreas de escala 1:40000 del proyecto TERRA, del Centro Nacional Geoambiental y 3. Fotos infrarrojas de escala 1:40000, de la Misión CARTA 2003, del Programa Nacional de Investigaciones Aerotransportadas y Sensores Remotos (PRIAS). El anterior estudio se complementó con trabajo de campo, con el cual se obtuvo información morfotectónica, estructural y geológica relacionada con las diversas fallas que se discuten en el presente artículo.

Como resultado de la investigación neotectónica se logró determinar una conjunto de fallas dentro de la zona de estudio (Fig. 2), varias de la cuales se continúan fuera de la misma, tanto hacia el noroeste dentro de los Montes del Aguacate, como al sureste hasta las estribaciones NW de la cordillera de Talamanca (Fig. 1). El mismo incluye las fallas Purires (ramal de la falla Candelaria), Picagres, Zapote, Bajos de Jorco y Jaris, de movimiento predominante dextral y rumbo norte a noroeste, y varias estructuras transtensivas asociadas con estas fallas (Fig. 2). Igualmente, se identificó la zona transpresiva de Dragón. (Fig. 2). Finalmente, entre las anteriores estructuras de movimiento dextral, también se determinó la falla Junquillo, de movimiento sinestral y rumbo cercano al E-W (Fig. 2).

El estudio se complementó con una revisión de la sismicidad, de foco superficial $(<20 \mathrm{~km})$, ocurrida en la zona de Puriscal durante el año 1990, a partir de los estudios de Barquero et al. (1991b), Rojas \& Barquero (1991), Fernández (1995) y Fernández \& Pacheco (1998), cuya información base proviene de la Red Sismológica Nacional (RSN, UCR-ICE). Igualmente se revisó el trabajo de Güendel et al. (1990). Lo anterior permitió determinar la relación entre la secuencia sísmica superficial y las fallas definidas en este estudio, permitiendo concluir que las fuentes sísmicas principales que originaron la sismicidad fueron las fallas Purires y Picagres. Como se verá, es posible también relacionar una sismicidad menor con las fallas Jaris, Bajos de Jorco, Zapote y Junquillo.

\section{MARCO TECTÓNICO}

Costa Rica se encuentra localizada en el borde suroeste de la zona de subducción entre las placas Coco y Caribe (Fig. 1). La misma se caracteriza por temblores interplaca de bajocorrimiento, siendo los terremotos de la entrada del golfo de Nicoya, del 25 de marzo de 1990 (M 7,0 y M 7,1; Fig. 1), los últimos de gran magnitud ocurridos en el pacífico-central. Entre los efectos notables asociados con estos eventos, estuvo la actividad sísmica superficial, que se disparó en diversas fallas del interior del país inmediatamente después de la ocurrencia de estos sismos interplaca (Barquero et al., 1991a). Entre las secuencias sísmicas disparadas, destaca la de Puriscal de 1990 (Barquero et al., 1991a; Bilek et al., 2009).

Dentro de la placa cabalgante y a lo ancho de la región central del país se presenta el Cinturón Deformado del Centro de Costa Rica (CDCCR; Fig. 1), caracterizado por fallas activas sinestrales de rumbo E a NE y dextrales de rumbo $\mathrm{N}$ a NW (Marshall et al., 2000; Montero, 2001; Montero et al., 2013). El origen del CDCCR se relaciona con la colisión del levantamiento del Coco con el sur de Costa Rica (Montero, 1994; Marshall et al., 2000; Montero et al., 2013; Fig. 1), un evento tectónico que se inició hace alrededor de 2-3 Ma (MacMillan et al., 2004; Morell et al., 2012).

La zona de estudio se ubica dentro del sector central-oeste del CDCCR, entre los paleoarcos volcánicos del Aguacate y de la cordillera de Talamanca (Fig. 1). Este magmatismo intruyó a través de rocas sedimentarias, que fueron depositadas en la paleocuenca Candelaria hasta el Mioceno Medio (Denyer \& Arias, 1991; Marshall et al., 2003). De acuerdo con Denyer \& Arias (1991), la actividad en el paleoarco volcánico del Aguacate tuvo dos episodios principales, los cuales originaron los depósitos de las formaciones La Cruz del Mioceno Superior y Grifo Alto del PliocenoPleistoceno; ambas se encuentran aflorando en forma amplia dentro de la zona de estudio. En el límite Mioceno-Plioceno, un importante evento tectónico ocurrió en la zona de estudio, el cual basculó al norte la secuencia sedimentaria y los depósitos volcánicos de la formación La Cruz 


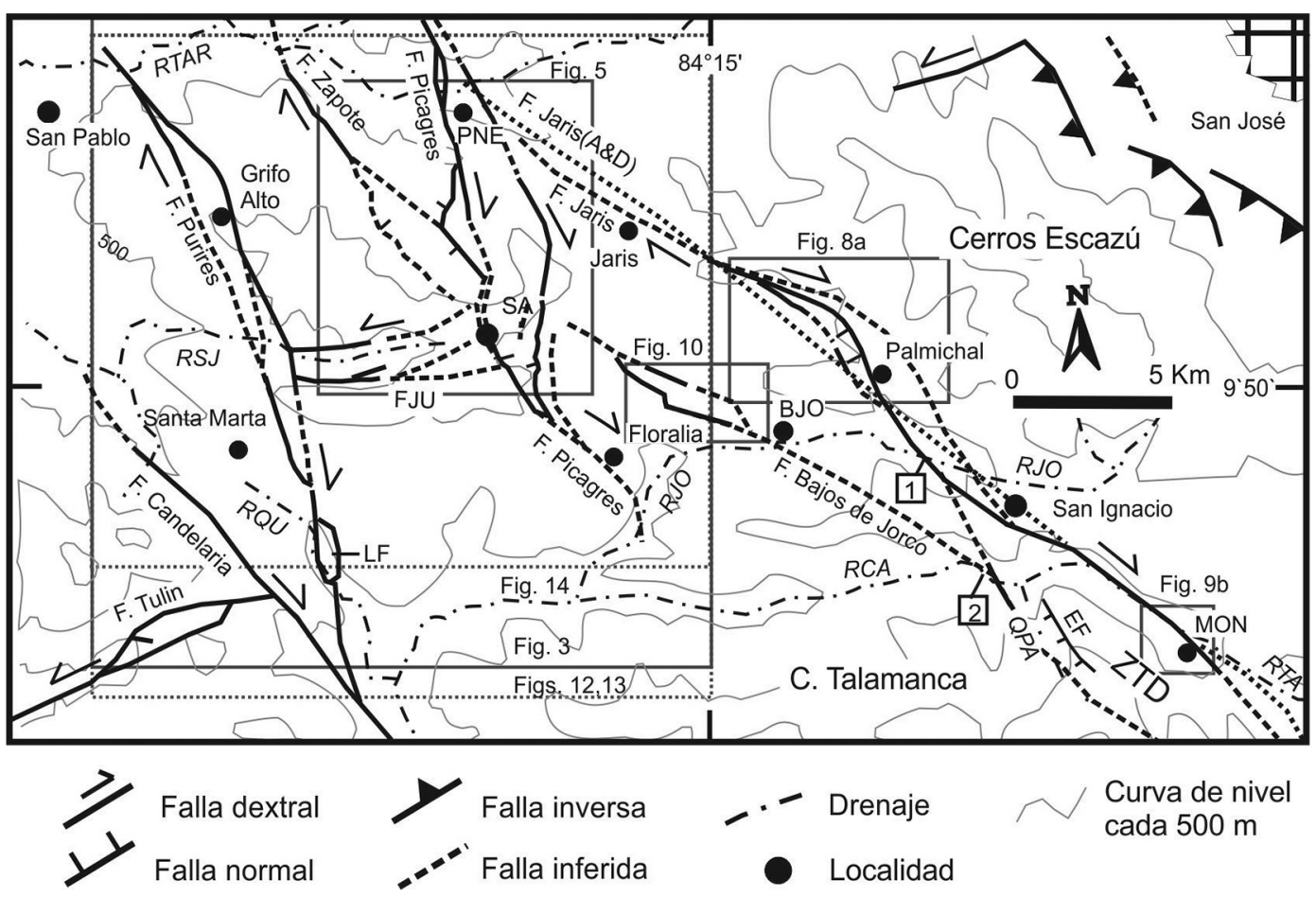

Fig. 2: Neotectónica de la zona de estudio. Muestra las fallas dextrales Purires, Zapote, Picagres, Bajos de Jorco y Jaris y la sinestral Junquillo (FJU) investigadas en el estudio. El trazo a puntos (indicada como F. Jaris (A\&D) es la falla Jaris mostrada en el estudio de Arias \& Denyer (1991a). ZTD es la zona transpresiva de Dragón. LF y EF son respectivamente un lomo de falla y el escarpe de falla (indicado por línea negra con líneas cortas) del lado este de la quebrada Pacayas (QPA). Los cuadrados con números indican la ubicación de sitios referidos en el texto. RTAR, RSJ, RQU, RJO, RCA y RTA son respectivamente los ríos Tárcoles, San José, Quivel, Jorco, Candelaria y Tarrazú. PNE, BJO y MON son respectivamente las localidades de Piedras Negras, Bajos de Jorco y Monterrey. Los rectángulos en gris o en puntos gris muestran las áreas que cubren las figuras 3, 5, 8a, 9b, 10, 12,13 y 14.

(Denyer \& Arias, 1991; Arias \& Denyer, 1991a). Asimismo, el magmatismo del paleoarco de la cordillera de Talamanca terminó en el Mioceno Tardío (antes de 5-8 Ma; Morell et al., 2012). Ambos eventos geológicos se relacionan con la colisión del levantamiento del Coco con el sur de Costa Rica (Arias \& Denyer, 1991a; Morell et al., 2012). Esta colisión ha provocado el escape tectónico del bloque del antearco centroamericano a una tasa de entre 8 a 11 mm/año (Fig. 1; LaFemina et al., 2009; Feng et al., 2012). La zona de estudio se localiza en el sector trasero de la zona de escape tectónico del anterior bloque (Lewis et al., 2008; Montero et al., 2013).

La investigación geológica previa a la ocurrencia de la secuencia sísmica de Puriscal de 1990, destacaba a las fallas Jaris y Candelaria como las principales estructuras tectónicas de la zona de estudio (Dóndoli \& Chaves, 1968; Castillo, 1969; Fig. 2). En una investigación sismológica previa a la actividad sísmica de 1990, Montero \& Morales (1984) usando datos aportados por redes sísmicas temporales y con el apoyo de las estaciones sísmicas fijas de la RSN (UCR-ICE), localizaron microtemblores de foco somero $(<15$ $\mathrm{km}$ de profundidad), ocurridos entre 1980 y 1981. Algunos de los epicentros que determinaron tuvieron una posición intermedia entre las fallas Jaris y Candelaria y una ubicación similar a la que tuvo la posterior sismicidad de 1990, lo cual permitió revelar una actividad sísmica asociada con fallas diferentes a las cartografiadas en estudios precedentes. Este resultado es confirmado en esta investigación, la cual describe con detalle, las 
características neotectónicas de las fallas que originaron la secuencia sísmica de Puriscal de 1990. Se debe destacar que con estas fallas se asocia una importante amenaza sísmica, tanto porque se determinan trazas de algunas decenas de kilómetros de longitud, como por la cercanía que estas fallas tienen con respecto a varios centros de población importantes ubicados en el centro-oeste de Costa Rica.

\section{RESULTADOS}

\section{La falla Purires y su relación con la falla Candelaria}

La falla Purires se describe por primera vez en este trabajo. La falla Purires con movimiento predominante dextral y una extensión dentro del área de estudio cercana a los $25 \mathrm{~km}$, se considera un ramal de la falla Candelaria (Figs. 2 y 3). Al noroeste se continúa al norte del río Tárcoles dentro de los Montes del Aguacate, donde no ha sido investigada en el campo. Tiene un rumbo predominante entre $\mathrm{N} 15^{\circ}-30^{\circ} \mathrm{W}$, hasta alcanzar la traza principal de la falla Candelaria, que tiene un rumbo $\mathrm{N} 40^{\circ} \mathrm{W}$. Al cruzar el río Grande de Tárcoles controla una vuelta a la derecha de unos $650 \mathrm{~m}$ de largo (Fig. 3). Al sureste de la localidad de Purires se divide en dos trazas que limitan una estructura transtensiva Entre las localidades de Purires y Cacao, la falla del lado oeste muestra un escarpe de falla facetado al NE (Fig. 3). Asimismo, hay claras evidencias de movimiento reciente en el sitio 1 (Fig. 3B), donde se determinaron entre dos a tres trazas de falla en una zona de un ancho de unos 75 metros. A lo largo de estas trazas se definieron desvíos derechos y rupturas en el perfil de equilibrio de quebradas (Fig. 4A), lo cual ha originado zonas suamposas y pequeños saltos de agua. También, hay escarpes de falla en roca y en materiales recientes y se observó una cuña coluvial, al pie de un pequeño salto de agua. En el sitio 2 (Fig. 3B), se observaron lavas pliocénicas de la

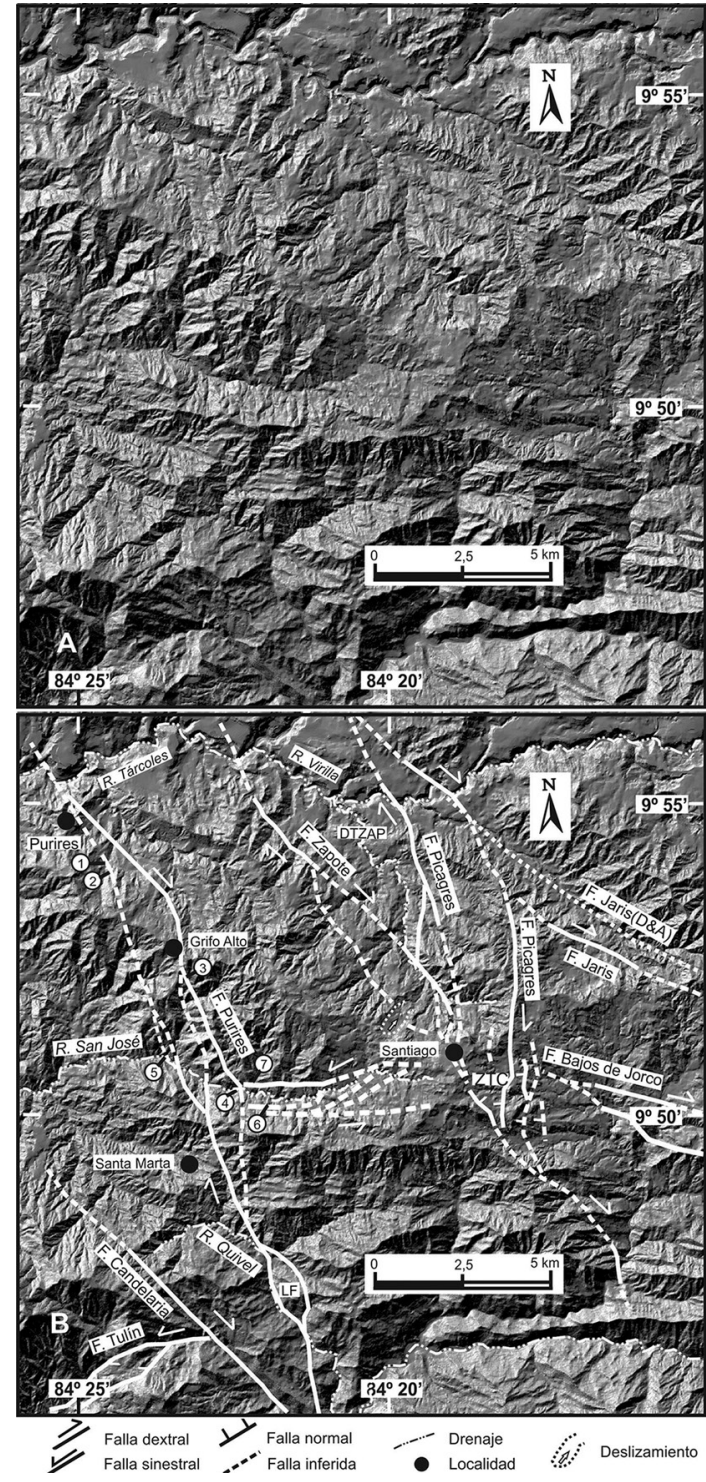

Fig. 3A: Modelo de sombras de la zona donde se localizan las fallas Purires y Picagres en el sector noroeste del área de estudio. Ubicación en Figura 2. B: Fallas interpretadas. F. Jaris (A\&D) es la falla Jaris mostrada en el estudio de Arias \& Denyer (1991a). DTZAP y ZTC son respectivamente la depresión tectónica de Zapote y la zona de tracción de Charcón. LF es el lomo de falla asociado con la falla Purires. Los círculos con números indican la ubicación de sitios referidos en el texto. 


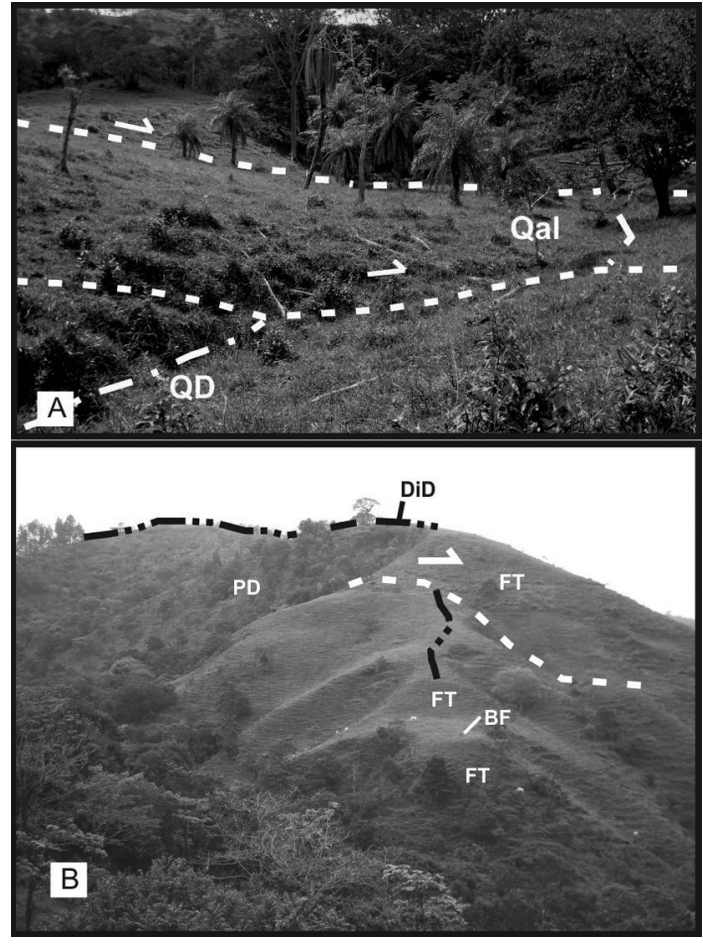

Fig. 4: A) Vista al SW de dos trazas de falla (a trazos blancos y flecha indica movimiento horizontal) ubicadas en el sitio 1 de la figura 3B, desplazando una quebrada (QD y trazo a línea y punto blancos) y depósitos aluviales recientes (Qal). B) Vista al NE de la falla Purires mostrando un escarpe de falla facetado al SW (con varias facetas FT), cortado por varias trazas de falla, de las cuales solo se muestra una con línea blanca a trazos (sitio 3 en Fig. 3B). Las diversas trazas originan descansos en la topografía o bermas de falla (BF) y divisorias desviadas (DiD), mostradas con doble punto y línea negra. PD es un paleodeslizamiento con un posible origen sísmico.

formación Grifo Alto (Arias \& Denyer, 1990b) sub-verticales y sobreyacidas por coluvios basculados al S, cerca de la traza de falla. Al sur de la localidad de Grifo Alto, en el sitio 3 (Fig. 3B), sobre la traza este de la falla, se observan valles lineales, quebradas descabezadas, divisorias desviadas, bermas de falla y escarpes de falla facetados al oeste (Fig. 4B). Al cruzar el río San José, el cauce se encañona y ocurre un desvío derecho del río entre ambas trazas de falla (indicado entre los sitios 4 y 5 en Fig. 3). Si se proyecta este desvío paralelo a la traza oeste de la falla, es de unos $2 \mathrm{~km}$ de longitud. Obsérvese que al oeste y este de la falla Purires, el río San José tiene un curso cercano al oeste, mientras que entre ambas trazas tiene un curso al NW. Al SE de la localidad de Santa Marta, las trazas que delimitan la estructura transtensiva se unen. Inmediatamente al sur de la unión anterior, al cruzar el río Quivel, se interpreta un lomo de falla (LF en Figs. 2 y 3), el cual se localiza sobre la margen izquierda del anterior río. Más al S, la falla alcanza la falla Candelaria.

En el mapa geológico de la hoja Candelaria de escala 1: 50000 del IGN (Denyer \& Arias, 1990b), la falla Purires pone en contacto las formaciones miocénicas Pacacua y Peña Negra. Arias \& Denyer (1991a) y Denyer \& Arias (1990b) interpretaron que el anterior contacto por falla ocurre a lo largo de la falla dextral Quivel, de rumbo noroeste.

\section{La falla Zapote}

Esta falla se describe por primera vez en este trabajo. Dentro de la zona de estudio, la falla posiblemente activa Zapote muestra dos trazas con rumbos entre NW a NNW. La traza que llega cerca de Santiago tiene un desplazamiento oblicuo dextral-normal y se extiende por al menos $12 \mathrm{~km}$, aunque en su sector sureste pierde expresión y es interrumpida por un deslizamiento drenado por la quebrada quebradilla (Figs. 2, 3 y 5). La traza que alcanza la falla Picagres, al pie de la fila Picagres, tiene rumbo NW, un desplazamiento dextral y una longitud de 4 km (Figs. 3 y 5). La falla Zapote se continúa al norte fuera de la zona de estudio, donde se puede seguir dentro de los Montes del Aguacate, pero no ha sido estudiada en el campo.

La componente normal de la falla Zapote es indicada por un escarpe de falla facetado al E, el cual es bastante persistente a lo largo del sector comprendido entre las localidades de Jateo y el sur de Desamparaditos (EF en Fig. 5; EF ZAP en 


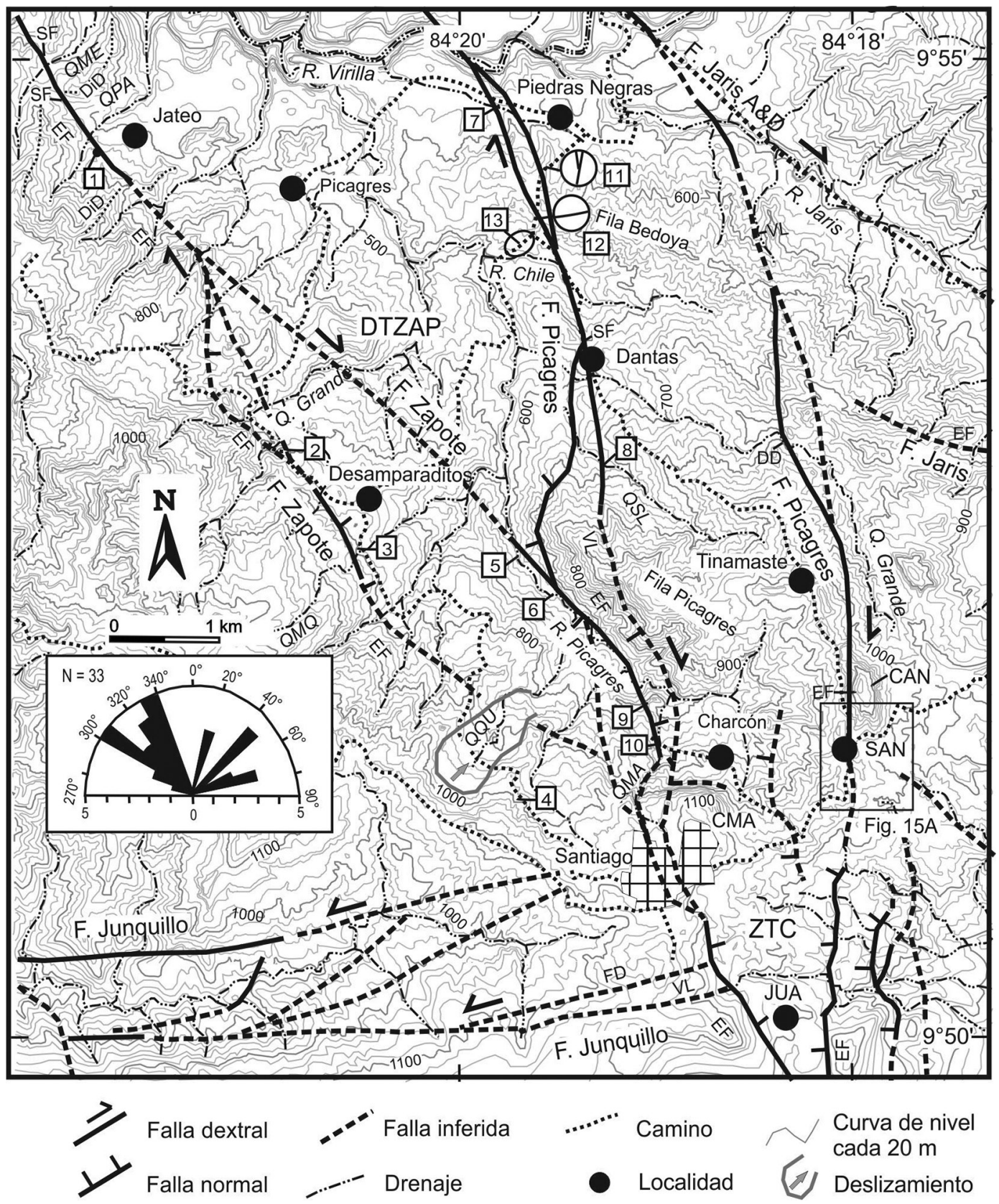

Fig. 5: Mapa neotectónico de Santiago de Puriscal y alrededores. Ubicación en figura 2. Se muestra el trazo de las fallas dextrales Zapote, Picagres y Jaris y la sinestral Junquillo. Además, se muestra el trazo con puntos de la falla Jaris reportada por Arias \& Denyer (1990b), a lo largo del valle del río Jaris. SF, EF, DiD, VL, DD y FD son respectivamente silla de falla, escarpe de falla, divisoria desviada (línea puntos negros fina), valle lineal, drenaje desviado y fila desviada. QME, QPA, QMQ, QQU, QMA y QSL son respectivamente las quebradas Mesas, Pacayal, Máquina, Quebradilla, Marín y Salitrales. CMA es el cerro Marín. JUA y SAN son respectivamente las localidades de Junquillo Abajo y de San Antonio. DTZAP y ZTC son respectivamente la depresión tectónica de Zapote y la zona de tracción de Charcón. Los cuadrados con números indican la ubicación de sitios referidos en el texto. Los sitios 11, 12 y 13 ubican observaciones de campo recopiladas inmediatamente después del terremoto del 22 de diciembre de 
figura 6C). Se considera que el lado norte del cerro Marín es la terminación al $\mathrm{E}$ del escarpe de falla Zapote, pero este sector de la falla ha sido desplazado dextralmente por las trazas de la falla Picagres, que lo cortan en su lado oeste. El basculamiento al suroeste de la superficie donde se asienta Santiago se relaciona parcialmente con la falla Zapote (Figs. 6B y 6C), aunque también con el movimiento de hundimiento que ocurre dentro de la zona de tracción de Charcón (ver adelante). La componente normal de la falla Zapote provoca que la morfología del lado E de la falla se observe relativamente deprimida, originando la depresión tectónica Zapote (DTZAP en Figs. 3, 5 y 6C).

La componente dextral de la falla Zapote es indicada principalmente por el desvío de quebradas y de divisorias. Por ejemplo, al noroeste de la localidad de Jateo ocurre el desvío derecho de las quebradas Mesas y Pacayal y de la divisoria entre ambas quebradas y de lado este de la última (DiD, Fig. 5). En esta zona también hay sillas de fallas (SF, Fig. 5). Entre Jateo, Desamparaditos y el norte de Santiago se observan desvíos derechos en varias quebradas. En el sitio 1 (Fig. 5), ocurre el desvío de drenajes intermitentes afluentes de la quebrada Pacayal, de divisorias y de un depósito aluvial, y existe una zona de suampo, mal drenada a lo largo de la traza de falla (Fig. 6A). En el sitio 2 (Fig. 5), Arias \& Denyer (1991b) reportan una zona de falla entre rocas de las formaciones La Cruz y Grifo Alto. Esta tiene un buzamiento promedio de $75^{\circ}$ al $\mathrm{E}$ y estrías buzando entre $15^{\circ}$ y $20^{\circ}$ inclinando al SE, consistentes con componentes derecha y normal en la falla. Movimiento con componente normal se infiere en el sitio 3 (Fig. 5), donde una terraza fluvial está basculada al SSW, en la margen izquierda de la quebrada Máquina. Más al SE, en el sitio 4 (Fig. 5), una secuencia de flujos piroclásticos de la formación Grifo Alto se observan basculados $40^{\circ}$ al $\mathrm{S} 50^{\circ} \mathrm{W}$, en el lado levantado por la falla.

Con respecto a la traza de falla que corta transversalmente la depresión tectónica de Zapote (cross-basin fault, McClay \& Dooley, 1995), la misma se evidencia por drenajes desviados, sillas de falla y escarpes facetados (Figs. 3 y 5). Entre los drenajes desviados más notorios está el de la quebrada Grande (Figs. 3 y 5). Asimismo, en la zona adyacente al lecho del río Picagres, Montero et al. (1990; 1991a y b y notas de campo adicionales) determinaron una zona de falla sub-vertical, con alteración hidrotermal y con fallas de rumbos entre $\mathrm{N} 0^{\circ}-34^{\circ} \mathrm{W}$ (sitio 5 en Fig. 5). Varias fallas afectando depósitos volcánicos, y cubiertas por un aluvión, tienen estrías horizontales. Fracturas con rumbo $\mathrm{N} 45^{\circ} \mathrm{W}$ fueron observadas cortando el sedimento aluvial. Al suroeste y adyacente a la zona de falla, se observó un coluvio basculado al oeste. En esta zona ocurre un contacto por falla entre la formación pliocénica Grifo Alto (lado oeste) y la formación miocénica La Cruz (lado este) (Arias \& Denyer, 1991b). En el sitio 6 (Fig. 5), Montero et al. (1991 a y b) reportaron dos lomos de falla escalonados con rumbos entre $\mathrm{N} 30^{\circ}-40^{\circ} \mathrm{W}$, prácticamente paralelos al rumbo de la falla, donde afloran depósitos aluviales levemente plegados y uno de ellos es cortado por una falla de rumbo $\mathrm{N} 33^{\circ} \mathrm{W}$ y buzamiento $71^{\circ} \mathrm{SW}$, con una componente normal. En el mismo trecho del río, se determinó una falla con componente normal de rumbo $\mathrm{N} 35^{\circ} \mathrm{W}$ y buzamiento $50^{\circ} \mathrm{NE}$ y otra con componente inversa de rumbo $\mathrm{N} 18^{\circ} \mathrm{W}$ y buzamiento $78^{\circ} \mathrm{SW}$, que terminan contra otra falla con componente normal dentro de depósitos coluvio-aluviales (Montero et al., 1991 a y b y notas de campo adicionales). Este último sitio se ubica donde la falla Zapote alcanza a la falla Picagres (Fig. 5).

\section{La falla Picagres}

El trazo propuesto para la falla Picagres en este estudio difiere sustancialmente del sugerido previamente por Montero et al. (1990; 1991 a y b) y Arias \& Denyer (1991b). Asimismo, se ha determinado que es de mayor longitud que lo sugerido

1990 (M 5,7). Para el sitio 11 se muestra el rumbo de las fracturas observadas. Para el sitio 12, la dirección ENE de una fractura abierta. Para el sitio 13, la zona del camino (encerrada dentro de elipse) donde se observaron diversas fracturas. En el recuadro se muestra el diagrama de la rosa de rumbos para las 33 fracturas medidas en el sector del camino localizado dentro de la elipse del sitio 13. El rectángulo en negro delgado muestra la ubicación de la figura 15A. 


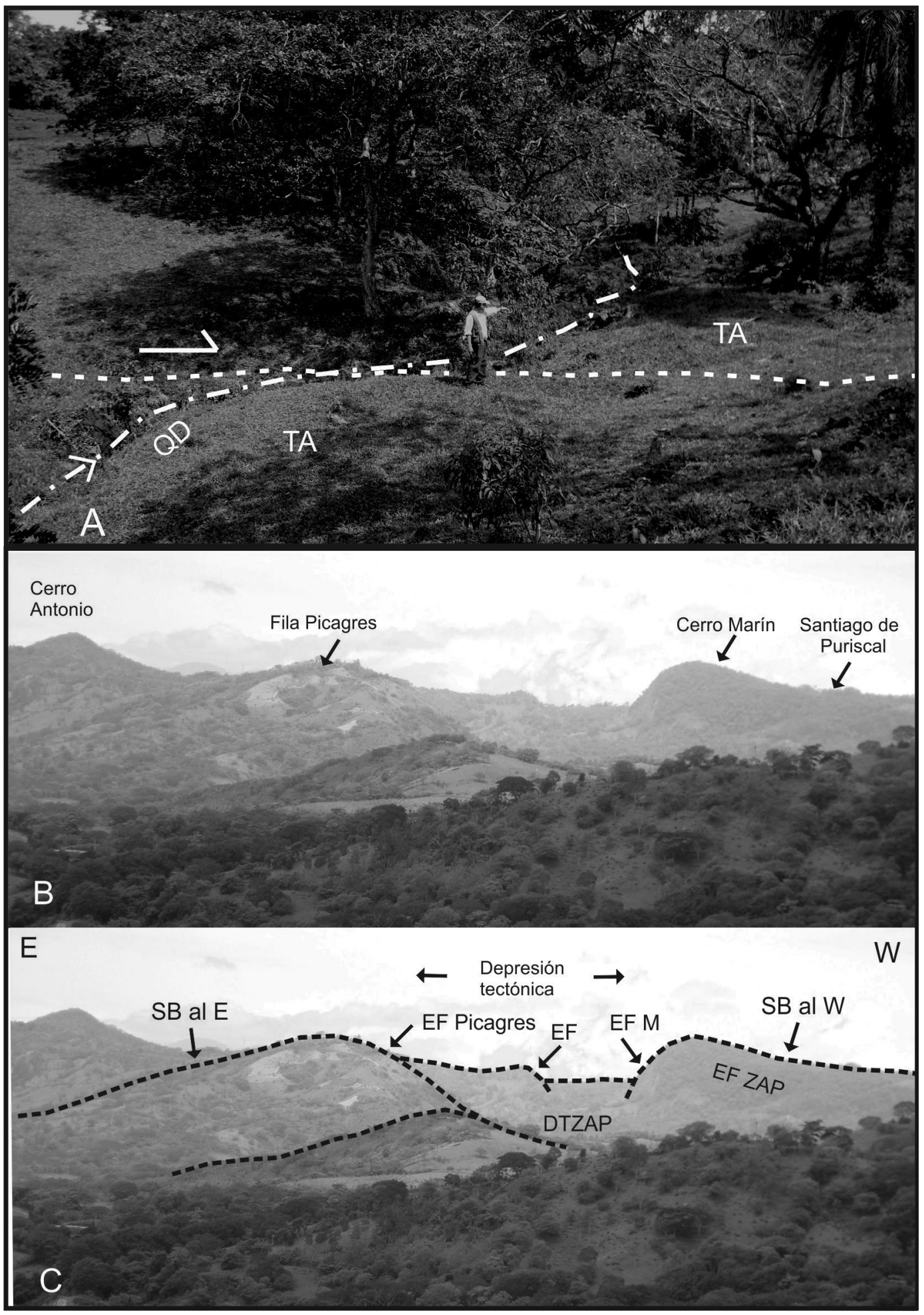


en estudios previos, dado que la misma es de unos $18 \mathrm{~km}$ dentro de la zona de estudio (Figs. 2, $3 \mathrm{y}$ 5). Al N se continúa fuera del área de estudio (Fig. 1). Dentro de la zona de estudio, la falla presenta dos trazas que delimitan la estructura transtensiva de Charcón, la cual se define mejor en el sector comprendido entre las localidades de Charcón y de Junquillo Abajo (Fig. 5). Este nombre fue usado previamente por Montero et al. (1990; 1991a y b) para una estructura similar identificada al este de Santiago de Puriscal, pero que en este estudio se delimita mejor con base en diversas evidencias, especialmente morfotectónicas.

Al cruzar el río Virilla, las dos trazas de la falla Picagres originan vueltas lineales al noroeste y a la derecha en el cañón del río. La del lado E es de $600 \mathrm{~m}$ y la del lado $\mathrm{W}$ de $700 \mathrm{~m}$, dando un acumulado de $1,3 \mathrm{~km}$ de desplazamiento, aunque es posible que ambas vueltas sean en parte erosivas considerando el caudal del río. Al oeste de la localidad de Piedras Negras, la traza oeste de la falla Picagres, origina una grada facetada al $\mathrm{W}$ en el camino que une la anterior localidad con la de Picagres y al sur de este camino se observa un desvío derecho en el cauce de una quebrada sin nombre, afluente del río Virilla (sitio 7 en Fig. 5). Al S de la fila Bedoya, esta traza sugiere originar un desvío derecho en el río Chile de unos $500 \mathrm{~m}$ de longitud. Al sur del río Chile, a lo largo de ambos taludes del camino que lleva a la localidad de Dantas, se observaron numerosas fallas con estrías, mostrando componentes de rumbo y de inclinación, cortando los depósitos volcánicos de la formación La Cruz. Arias \& Denyer (1991b) también reportaron varias fallas en este sector.

Al sur de la localidad de Dantas, la traza oeste se divide en dos trazas, las cuales muestran sillas de falla, valles lineales, desvío de drenajes y escarpes facetados (Fig. 5). Por ejemplo, al sur de la localidad de Dantas sugiere desviar la quebrada
Salitrales (sitio 8 en Fig. 5). Del lado oeste de la fila asimétrica Picagres, la traza oeste de la falla muestra quebradas desviadas o alineadas y un escarpe prominente facetado al SW de unos 200 $\mathrm{m}$ de altura, cuya pendiente es más tendida hacia el noreste (Figs. 5, 6B y 6C). En el escarpe de falla se observan descansos entre las estribaciones facetadas, estructura en copa de vino y varios afluentes del río Picagres tienen valles profundos con cascadas, desplazados dextralmente y divisorias con ganchos de falla derechos, evidenciando las componentes normal y dextral de la falla (Fig. 7A; Montero et al., 1990; 1991a y b). En este sector, la falla Picagres es el límite este de la depresión tectónica de Zapote.

Más al sureste, al salir del valle del río Picagres, las trazas oeste de la falla Picagres tienen un cambio de rumbo al $\mathrm{S}$ pasando por sillas de falla y lomas facetadas (sitio 9, Fig. 5). Al cruzar la margen izquierda de la quebrada Marín, en el talud de un camino al oeste de Charcón y del lado norte del escarpe de falla del cerro Marín, se presenta una secuencia fuertemente basculada $\left(55^{\circ}\right.$ al $\mathrm{S} 62^{\circ} \mathrm{E}$ ), donde una lava sobreyace a un aluvión, ambos depósitos pertenecientes a la formación $\mathrm{La}$ Cruz (sitio 10 en Fig. 5; Arias \& Denyer, 1991; Montero et al., 1990; 1991a y b). Esta secuencia, se encuentra separada normalmente por una falla de rumbo $\mathrm{N} 40^{\circ} \mathrm{W}$ y buzamiento $75^{\circ} \mathrm{NE}$.

La falla Picagres en su lado oeste mantiene las dos trazas al cortar el cerro Marín (Fig. 5). Ambas trazas originan el desvío derecho del escarpe facetado al norte del cerro Marín y tienen un rumbo N-S, dentro de la ciudad de Santiago de Puriscal. En el sector norte de la ciudad, entre ambas trazas se origina un bloque ligeramente levantado. La vieja iglesia de Santiago se localiza dentro de este bloque. La que sigue el curso de la quebrada Marín es facetada al W, mientras que la del lado este es facetada al E. Sin embargo, estos

Fig. 6: A) Vista al norte de la falla Zapote originando un desvío derecho en una quebrada (QD y línea y punto) y en una terraza aluvial (TA), localizada sobre la margen derecha. Ubicación del sitio 1 en la figura 5. B) Vista al S de diferentes elementos geográficos y morfológicos que definen la depresión entre las fallas Zapote y Picagres (depresión tectónica Zapote). C) Interpretación de la fotografía mostrada en B definiendo los diferentes elementos morfoestructurales que limitan la depresión tectónica Zapote (DTZAP). EF ZAP es el escarpe de falla que caracteriza a la falla Zapote en este sector. Se muestra el basculamiento del lado oeste del cerro Marín (SB al W) y de la fila Picagres al E (SB al E). Obsérvese como el basculamiento aumenta hacia el escarpe de falla del cerro Marín (EF M). Además, se muestra el escarpe de falla Picagres y de una falla del lado este de la zona transtensiva de Charcón (EF). 
escarpes disminuyen en altura de norte a sur hasta unirse en el lado sur de la ciudad. Como se explicó breviamente, el efecto tectónico conjunto de estas trazas de la falla Picagres interactuando con la falla Zapote, es el que origina el basculamiento al SW de la superficie sobre la cual se asienta la ciudad de Santiago de Puriscal (Figs. 6B y 6C). Al sur de Santiago, la traza oeste de la falla Picagres muestra un escarpe de falla facetado al E (Figs. 5 y 7B).

Con relación a la traza este de la falla Picagres, donde cruza el río Jaris origina una cascada y un valle ancho del lado oeste de la falla (Fig. 5). Al sur del anterior sitio, cruza la fila Bedoya, donde muestra morfologías juveniles tales como valles lineales, desvío de divisorias y desvío de drenajes, como el de la quebrada Grande, la cual a su vez tiene un curso sub-paralelo a la falla en su curso superior (Fig. 5). La falla se localiza sobre las estribaciones oeste del valle de esta quebrada. Al salir de este valle al norte de la localidad de San Antonio, se ubica del lado oeste del cerro Antonio, el cual se muestra con un escarpe facetado al oeste (Fig. 5). Asimismo, del lado este de la localidad de Charcón muestra escarpes de falla facetados al oeste. Al este y sureste de Santiago se observan varias trazas caracterizadas por escarpes de falla facetados al oeste, con alturas de unas pocas decenas de metros (por ejemplo, escarpe EF en la figura 6C). Se han identificado al menos tres trazas en este sector de la falla Picagres, $\mathrm{Al}$ este de Junquillo Abajo se muestra un claro escarpe de falla facetado al oeste, pero existen otros dos al este del anterior (Fig. 5). Al este y sureste de Santiago, las trazas de falla Picagres del lado oeste y este definen una zona de tracción que se denomina de Charcón (ZTC en Fig. 5). Más al sur, las trazas oeste y este de la falla Picagres se unen (Fig. 3).

Al sur de la localidad de Floralia, la falla pierde expresión y se puede continuar hasta cerca del cauce del río Jorco (Fig. 2). Este sector de la falla no fue estudiado en el campo, debido a dificultades de acceso.

\section{La falla Jaris: morfotectónica y estructura}

\section{Estudios previos}

La falla Jaris aparece en diversos mapas geológicos de la zona central de Costa Rica desde la segunda mitad del siglo XX. Entre estos destacan los de Dóndoli y Chaves (1968), Castillo (1969), Denyer \& Montero (1988), Arias \& Denyer (1990a y b) y Denyer \& Arias (1990a). En los trabajos de Castillo (1969), Arias \& Denyer (1990a y b) y Denyer \& Arias (1990a) se muestra como una falla de desplazamiento dextral de rumbo aproximado $\mathrm{N} 50^{\circ}-60^{\circ} \mathrm{W}$. En los mapas geológicos de las hojas Río Grande, Abra y Caraigres de escala 1:50000 del IGN, se extiende en forma lineal por unos $42 \mathrm{~km}$, terminando al NW al salir del valle del río Jaris y al sureste se continúa fuera de la hoja Caraigres (Arias \& Denyer, 1990a y b; Denyer \& Arias, 1990a; Fig. 2). Arias \& Denyer (1990a; 1991a) citan diversos criterios de reconocimiento de la falla Jaris, aunque no mencionan evidencia de actividad neotectónica. La falla recibe este nombre por su trazo lineal a lo largo del valle del río Jaris. Sin embargo, como veremos, nuestro cartografiado de la falla Jaris, difiere con respecto a la anterior interpretación, dado que no se encontró evidencia de que la falla Jaris tenga un trazo subparalelo con el río Jaris. Sin embargo, debemos destacar que nuestro trazo es para una falla neotectónica y podría ser que un trazo subparalelo al del río Jaris corresponda con un trazo actualmente inactivo. A pesar de lo anterior, en términos generales, nuestro trazo de la falla Jaris coincide en varios sectores con los de Arias \& Denyer (1990a y b) y Denyer \& Arias (1990a) (ver Fig. 2). Considerando este último aspecto y el hecho de que la falla tenga un trazo muy cercano al poblado de Jaris, se estimó conveniente mantener el nombre de falla Jaris para la falla descrita en este trabajo. Asimismo, nuestra interpretación define una serie de fallas conectadas, el cual se denomina como sistema de falla Jaris. 


\section{Nuevos hallazgos}

En concordancia con Arias \& Denyer (1990a y b, 1991a) y Denyer \& Arias (1990a), se define la falla Jaris como una falla de movimiento predominante dextral y un rumbo general $\mathrm{N} 40^{\circ}-60^{\circ} \mathrm{W}$ (Fig. 2). Es una falla regional que se extiende al menos $45 \mathrm{~km}$, entre el SE de la localidad de Piedras Negras al NW y el flanco NW de la cordillera de Talamanca al SE (Figs. 1 y 2). Esta falla fue estudiada en el campo dentro de los límites definidos en la figura 2.

Al noroeste, la falla Jaris puede continuarse con la falla Picagres (figs. 3 y 5). En este sector la falla se caracteriza por escarpes de falla, facetados principalmente al suroeste. Una zona transtensiva relacionada con un cambio de rumbo de WNW a NNW caracteriza a la falla Jaris en el sector cercano a las localidades de Tabarcia y Palmichal (Fig. 2). Esta zona transtensiva incluye tres trazas. Las dos trazas que se localizan cerca de la localidad de Corrolar se evidencian por desvíos derechos en los ríos Cañas y Tabarcia y en las quebradas Mónica y Mina (Fig. 8A). Al cruzar la estribación entre esta última quebrada y el río Cañas, se observaron claras evidencias de la actividad holócenica de la falla, incluyendo morfologías juveniles asociadas con el desvío de divisorias, quebradas desviadas a la derecha, una terraza aluvial asociada con el río Cañas posiblemente desviada y una zona transtensiva deprimida y limitada por escarpes de falla (sitio 1 en Fig. 8A, Fig. 8B). Entre las localidades de Corrolar y de Palmichal, la falla se caracteriza por un escarpe de falla facetado al W, el cual limita las estribaciones suroeste de los cerros de Escazú (Figs. 2 y 8). El escarpe de falla muestra varias generaciones de facetas. Al pie del mismo, se observan varios niveles de terrazas aluviales y flujos de debris depositados principalmente por los ríos Tabarcia y Cañas. El relleno aluvial se extiende aguas abajo hasta el estrangulamiento del valle del río Tabarcia al suroeste, que puede relacionarse con la falla Bajos de Jorco (ver adelante).
Esta zona de depósitos aluviales anómala ubicada dentro de una zona de montaña, se explica porque la falla Jaris tiene una fuerte componente normal en los sectores con rumbo NNW. El levantamiento relativo del bloque E de la falla a lo largo del Cuaternario, ha originado un importante depósito de sedimentos aluviales en el bloque $\mathrm{W}$, relativamente hundido. Asimismo, existe un marcado contraste topográfico entre el sector de los cerros de Escazú, que muestra una topografía juvenil en pleno levantamiento y la zona del lado oeste de la falla, que muestra una topografía bastante erosionada y disectada (Fig. 8A). Un contraste en la geología también se presenta a ambos lados de la falla, donde la formación sedimentaria Peña Negra de edad miocénica, se levanta del lado este de la falla, mientras que del lado oeste afloran las formaciones volcánicas La Cruz y Grifo Alto (Fig. 7A; Denyer \& Arias, 1990a). Una traza de falla ubicada dentro de los cerros de Escazú, se evidencia por valles lineales, el inicio de la depositación aluvial aguas arriba, escarpes facetados y una divisoria desviada (Fig. 8A).

Al W de San Ignacio de Acosta, la falla Jaris origina un desvío a la derecha del río Jorco (Fig. 2). Al cruzar el río Jorco, tres niveles de terrazas recientes se observaron sobre la margen izquierda y del lado $\mathrm{N}$ de un escarpe de falla. Las mismas sugieren haber sido desplazadas por la falla, donde la más vieja se encuentra más al E con respecto al lugar donde la falla cruza el cauce del río (sitio 1 en Fig. 2). Inmediatamente al SE del cruce del río Jorco, la falla corta y desplaza tres colinas en forma sucesiva, las cuales muestran escarpes facetados al S (Fig. 9A).

La falla se divide en dos trazas al cruzar la fila de la margen sur del río Jorco originando la zona transpresiva de Dragón, que morfológicamente corresponde con un lomo de falla (Fig. 2). Al SE de San Ignacio de Acosta, la traza E de la falla se alinea con el río Candelaria a lo largo de un valle de falla, donde se observa facetamiento triangular en la margen izquierda y rectangular en la margen 


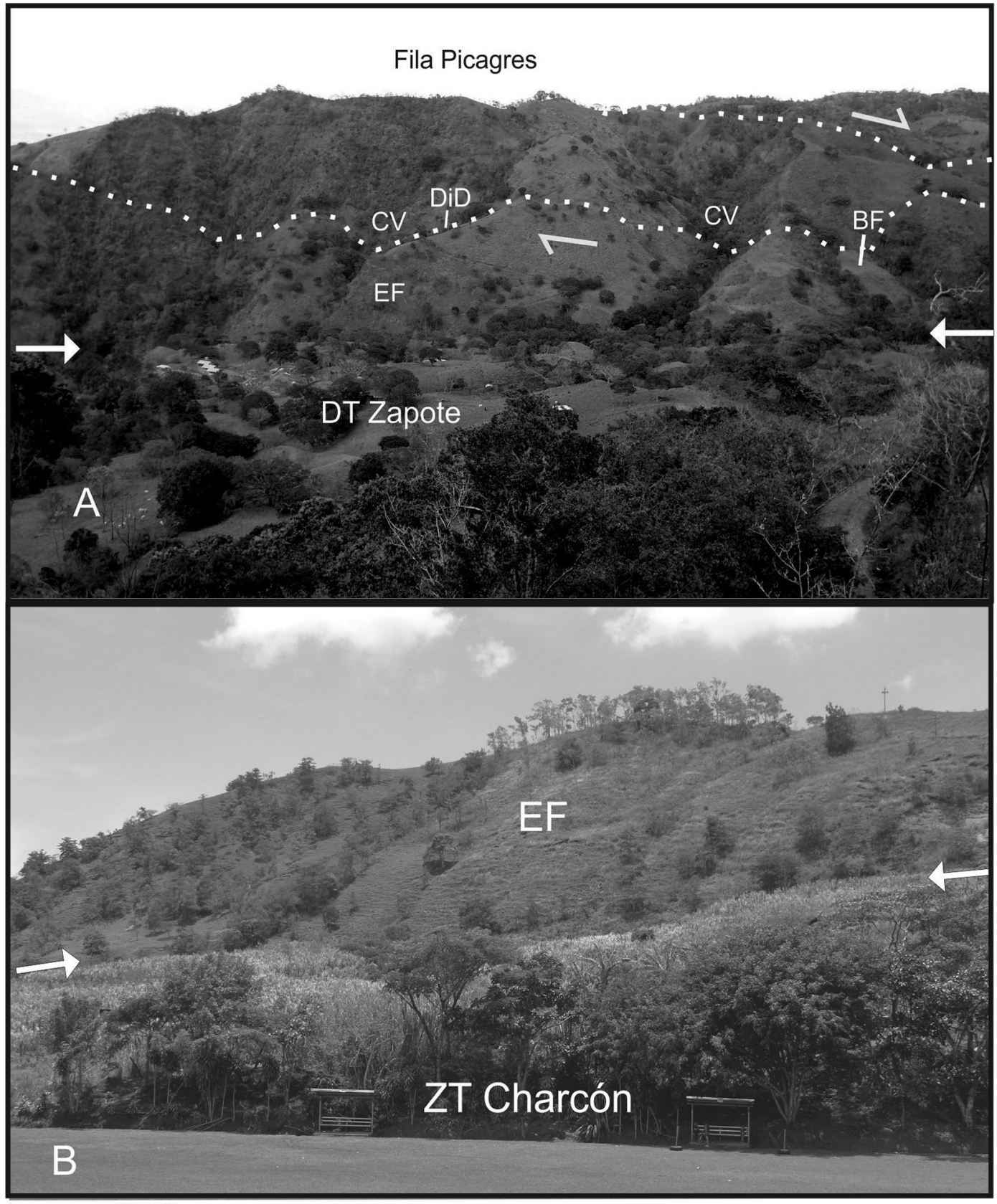

Fig. 7: A) Vista al este del escarpe de la falla Picagres (definida entre flechas) y de la depresión tectónica de Zapote (DT Zapote) ubicada del lado oeste del mismo. Las líneas a puntos blancos ubican dos trazas de falla del sector oeste de la falla Picagres. CV, EF, DiD y BF son respectivamente copa de vino, escarpe de falla, divisoria desviada y berma de falla. B) Vista al SW del escarpe de falla facetado al E, ubicado al oeste de Junquillo Abajo (JUA en fig. 5). La zona transtensiva de Charcón (ZT Charcón) se ubica al pie del mismo 
derecha. Asimismo, del lado sur de falla afloran rocas pertenecientes al Intrusivo de Escazú, del límite Plioceno-Mioceno, que intruyen rocas sedimentarias del Mioceno Medio de la formación Peña Negra (Arias \& Denyer, 1990a; Denyer \& Arias, 1991). Las rocas intrusivas están en contacto por falla contra los depósitos volcánicos de la formación La Cruz, que afloran del lado norte de la falla. Esta última formación es sobreyacida por la formación Grifo Alto (Arias \& Denyer, 1990a). El levantamiento asociado con la zona transpresiva de Dragón explicaría parcialmente el afloramiento de las rocas intrusivas relativamente jóvenes, indicadas anteriormente.

Al cruzar la falla cerca de la localidad de Monterrey, ocurre un importante depósito aluvial, observándose varios niveles de terrazas, donde confluyen los ríos Tarrazú, Caraigres y Santa Elena, que dan origen al río Candelaria (Fig. 9B). Se han determinado varias geoformas que sugieren el trazo de la falla en este sector, como son escarpes facetados, una divisoria desviada y quebradas desviadas (indicados respectivamente como EF, DiD y Qd en Fig. 9B). Con respecto a las terrazas, sus geometrías sugieren ser controladas parcialmente por la falla (Fig. 9B). En el sitio 1, al cruzar la falla la terraza T3 sobre la margen izquierda del río Caraigres, se observa un adelgazamiento de la terraza hacia la traza de falla, lo cual sugiere que un posible desvío derecho de la misma, pudo haber sido erosionado por el río. Asimismo, el borde rocoso que limita esta terraza al W muestra un leve desvío derecho. En el sitio 2 del lado norte de la traza de falla, se observa un saliente a la derecha en el escarpe de la terraza T2, sobre la margen izquierda del río Caraigres. En el sitio 3 se observa un saliente a la derecha en la terraza T3 del lado sur de la traza de falla. En el sitio 4 se observa que la terraza T3 tiene una flexión a la derecha al cruzar la traza de falla. Algo similar muestra el contacto entre las rocas volcánicas y la terraza localizada de lado E de la localidad de Monterrey. Esta terraza superior, sobre la cual se asienta Monterrey, muestra un ancho mayor del lado aguas abajo de la traza propuesta de falla, lo cual puede asociarse con un anterior desvío derecho del río. Asimismo, la terraza T1 se encuentra aflorando principalmente del lado sur de la falla y del lado interno de un saliente a la derecha formado por las terrazas T2 y T3. La fila que se localiza del lado E de la terraza T3 muestra desvíos derechos en sus bordes oeste y este, al igual que de su divisoria (DiD en Figura 9B). Igualmente, la fila al $\mathrm{S}$ de la traza de falla se muestra facetada al $\mathrm{N}$. Las anteriores geoformas sugieren una traza de falla de movimiento horizontal derecho y levantamiento del lado sur.

Al sureste de Monterrey, la traza este de la falla Jaris se localiza sobre las estribaciones sur del valle del río Tarrazú (Fig. 2) y se evidencia por escarpes facetados al norte y sur, sillas de falla, drenajes desviados y adaptados, desvío de colinas, entre otros.

Con respecto a la traza oeste de la zona transpresiva de Dragón, la misma origina un desvío derecho al cruzar el río Candelaria (sitio 2 en Fig. 2) y al sureste se localiza cerca del valle de la quebrada Pacayas, caracterizándose por un escarpe facetado al SW, que limita el lado E del valle de la anterior quebrada (Fig. 2). La traza oeste de la falla Jaris coincide parcialmente con la traza de la falla Resbalón de Arias \& Denyer (1990a).

Las trazas este y oeste del lomo de falla se reunifican en una sola traza al NW de San Pablo de León Cortés, cerca de donde la falla parece terminar al SE (Fig. 1).

\section{La falla Bajos de Jorco}

Al este de Santiago de Puriscal, la falla dextral Bajos de Jorco tiene un rumbo $\mathrm{N} 50^{\circ} \mathrm{W}$ hasta alcanzar la falla Jaris al SW de San Ignacio de Acosta (Fig. 2). Al cruzar la falla entre los ríos Viejo y Tabarcia, se determinaron dos trazas de falla y la divisoria de la colina entre ambos ríos es desviada por las mismas (Did en Fig. 10). La traza norte al cruzar el río Viejo origina un desvío derecho de $\sim 100$ m (Rd1 en Fig. 10) y hay una terraza aluvial sobre la margen izquierda del 

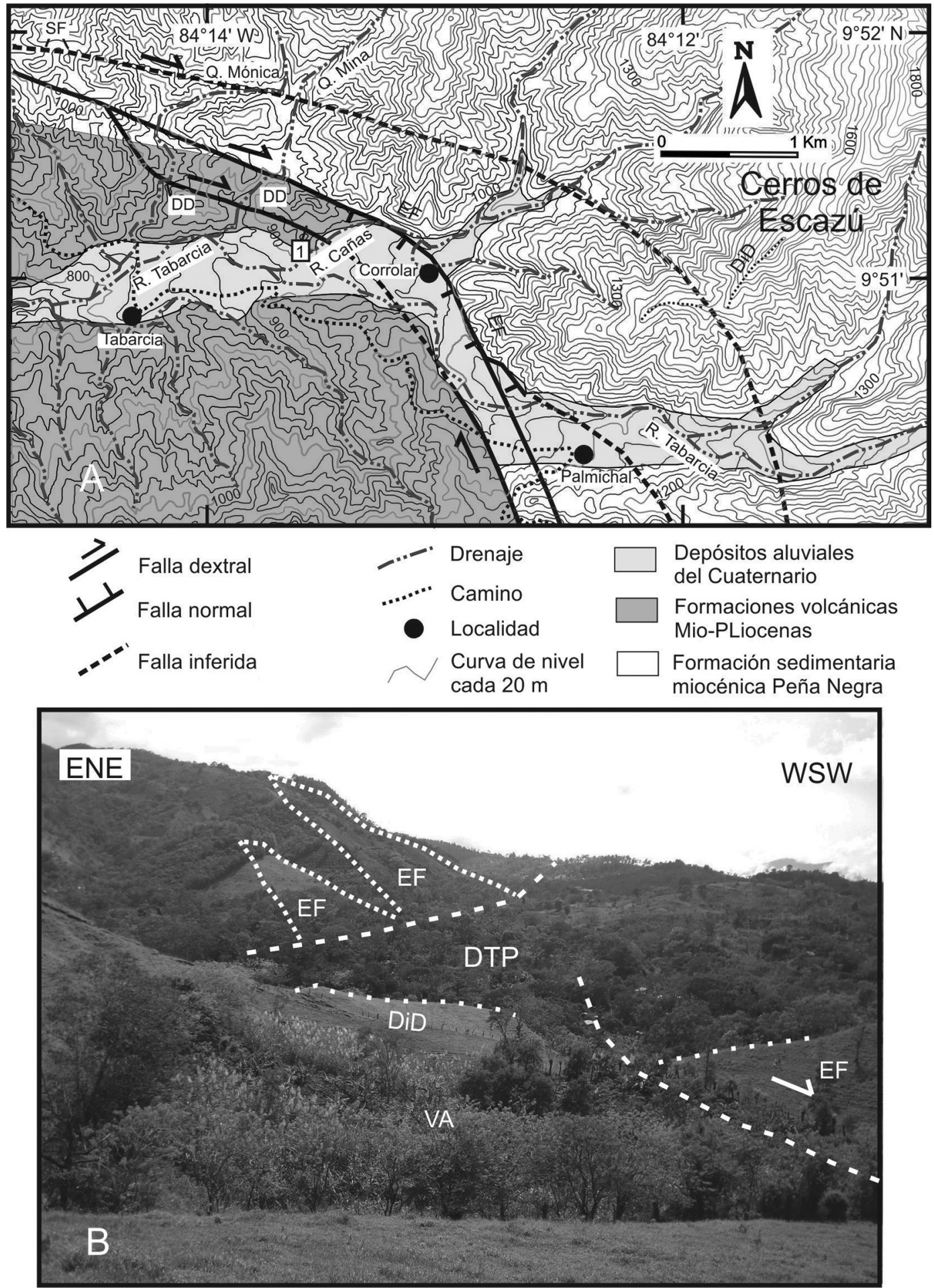
río. Del lado norte del lugar donde el ramal norte de la falla cruza el río Tabarcia, se ha originado un amplio relleno aluvial, sugiriendo un aluvial represado (Qr en Fig. 10). Un cambio litológico limitado por un escarpe de falla (Ef en Fig. 10) ocurre a ambos lados de la falla. Del lado sur del anterior ramal, el valle del río Tabarcia se estrangula originando un valle encañonado antecedente. El cambio litológico se puede relacionar con litologías contrapuestas de diferentes competencias, debido al desplazamiento asociado con la falla.

Con respecto a la traza sur, en su sector oeste, esta sugiere asociarse con una quebrada descabezada al inicio de la cual se observó una terraza aluvial (sitio 1 y Qdes en Fig. 10). Asimismo, la traza de falla origina desvíos derechos de los ríos Viejo (Rd2) y Tabarcia (Rd3). El desplazamiento acumulado entre las trazas norte y sur a lo largo del río Viejo es de $\sim 200 \mathrm{~m}$ (entre Rd1 y Rd2 en Fig. 10). Sin embargo, en el sitio 2 (Fig. 10) afloran depósitos aluviales pleistocenos, bastante meteorizados, unos $20 \mathrm{~m}$ sobre el nivel actual del río, los cuales se pueden asociar con viejos niveles del río Viejo desplazados, por lo cual el anterior desplazamiento puede ser aún mayor. El desvío derechos $\mathrm{Rd} 3$ del río Tabarcia, a lo largo de la traza sur es de $\sim 350 \mathrm{~m}$.

Evidencias adicionales que sugieren fallamiento reciente fueron encontradas en otros sitios en esta zona. Por ejemplo, sobre la margen derecha del río Viejo, lavas plegadas del lado norte están en contacto por falla con depósitos de flujos de debris cubiertos por una terraza aluvial en el sitio 3 (Fig. 10). El contacto por falla ocurre a lo largo de un escarpe facetado al sur. En el sitio 4 (Fig. 10) ocurre un contacto por falla entre lavas del lado norte con tobas del lado sur. La zona de falla está alterada hidrotermalmente e incluye fallas consistentes con una cupla dextral. En el sitio 5 , una terraza aluvial termina al oeste contra una traza de falla, sugiriendo un aluvión represado. En el sitio 6 hay una colina cuya divisoria está desviada a la derecha y del lado este de la misma, hay una zona deprimida anómala de rumbo N-S (De en Fig. 10), que parece igualmente desviada.

En los alrededores de la localidad de Bajos de Jorco (Fig. 2), la falla Bajos de Jorco muestra una expresión morfológica débil, aunque en el campo se observa una zona de alteración hidrotermal ancha, la cual se puede observar del lado oeste y este de la anterior localidad. Un desvío derecho del río Jorco se puede interpretar, donde la falla lo cruza, cerca de la anterior localidad. En la zona de unión con la falla Jaris, parece tener un trazo similar al de la falla Resbalón, que se muestra en el mapa geológico de la hoja Caraigres, elaborado por Arias \& Denyer $(1990,1991)$. Esta interpretación explica tanto el desvío derecho del río Jorco al sur de la localidad de Bajos de Jorco, como el del río Candelaria al suroeste de San Ignacio de Acosta (Fig. 2). Al sureste alcanza la traza oeste de la zona transpresiva de Dragón, asociada con la falla Jaris (Fig. 2).

\section{La falla Junquillo}

Constituye un conjunto de varias fallas de movimiento predominante sinestral, con un rumbo oscilante entre E-W y ENE, que tienen un patrón en abanico y una longitud de $7 \mathrm{~km}$ para las dos trazas principales que limitan el sistema, las

Fig. 8: A) Neotectónica de la falla Jaris entre las localidades de Tabarcia y Palmichal. En gris claro se muestra el considerable relleno lahárico-aluvial asociado con el levantamiento del bloque este de la falla en este sector. Asimismo, se muestra el contraste morfológico entre el sector oeste y este de la falla siendo más juvenil y levantado el último. SF, DD, EF y DiD son respectivamente silla de falla, drenaje desviado, escarpe de falla y divisoria desviada. La geología es modificada de Denyer \& Arias (1990a). El cuadrado con el número uno indica la ubicación de este sitio referido en el texto.Ubicación en Figura 2. 8B: En primer plano, vista al SE tomada desde el sitio 1 de la traza sur de la falla Jaris sobre la margen derecha del río Cañas (ver Fig. 8A), donde el movimiento derecho de la falla (línea a trazos) origina un valle abandonado. La falla se evidencia por un escarpe de falla (EF) y una divisoria desviada en forma derecha (líneas con puntos). Al fondo de la foto se muestra el escarpe de falla con su facetamiento triangular (EF), que caracteriza a la traza central de falla Jaris en este tramo (ver Fig. 8A) y que origina la depresión tectónica de Palmichal (DTP). 


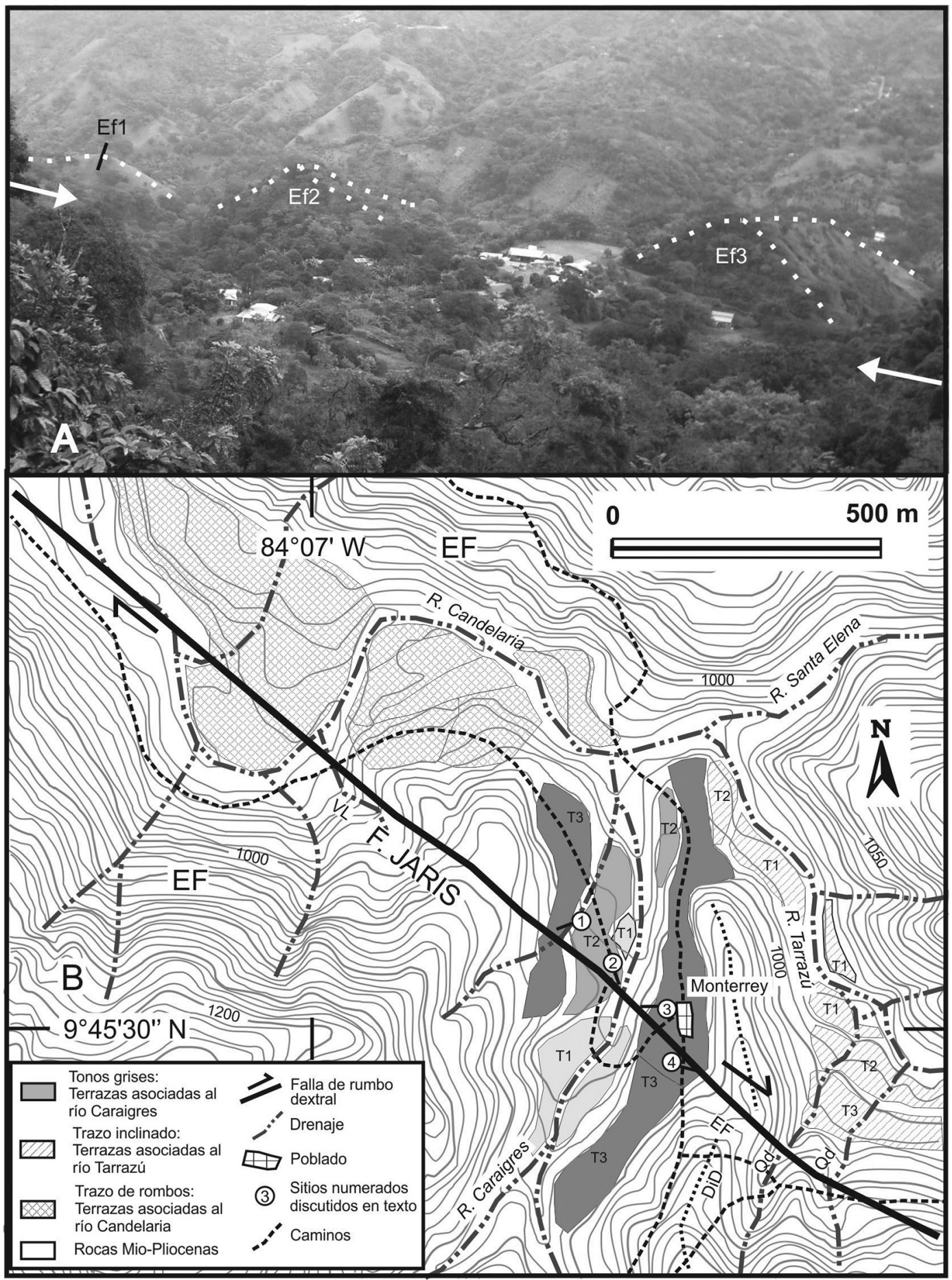


cuales se ubican del lado norte y sur del río San José (Figs. 2 y 3). El sistema de fallas termina al oeste contra la falla Purires y al este contra la falla Picagres (Figs. 2 y 3). La falla principal del lado sur del río San José, en su terminación al W, se divide en varias sub-trazas, que se identifican por mostrar estructura en copa de vino, escarpes de falla, valles lineales, drenajes desviados y adaptados, desvío de divisorias, entre otros (ubicación 6 en Fig. 3B; Fig. 11). Al suroeste de Santiago de Puriscal, esta falla se ubica dentro de una zona bastante poblada. Sin embargo, pueden interpretarse el trazo de la misma mediante filas desviadas y facetadas, valles lineales y quebradas desviadas (Fig. 5). La falla del lado norte del río San José muestra desvío de drenajes, sillas de falla, escarpes de falla, desvío de divisorias, entre otros. Uno de los drenajes desviados es el de la quebrada Guatuso, de unos $150 \mathrm{~m}$ de longitud (sitio 7 en Fig. 3B).

\section{LA SISMICIDAD DE PURISCAL DE 1990 Y SU RELACIÓN CON LAS FALLAS PURIRES Y PICAGRES}

La actividad sísmica de Puriscal fue disparada por los terremotos interplaca de la entrada del golfo de Nicoya del 25 de marzo de 1990 (M 7,0 y $\mathrm{M}_{\mathrm{s}}$ 7,1; Fig. 1) (Barquero et al., 1991a; Bilek et al., 2009). Güendel et al. (1990) localizaron la sismicidad de la zona de Puriscal para el período entre el 26 de marzo (un día después de los terremotos interplaca) y el 11 de julio de 1990 (once días posteriores al terremoto de Barbacoas del 30 de junio, $M_{s}$ 5,1) (Fig. 12). Entre el 26 de marzo y el 21 de abril, la actividad sísmica fue relativamente menor, localizándose algunos sismos en las fallas Tulín, Candelaria y Purires (círculos sin rellenar en Fig. 12). A partir del 24 de abril y hasta alrededor del 15 de junio ocurrió un enjambre sísmico, el cual se localizó principalmente dentro de una zona de forma elipsoidal de rumbo NNW (círculos rellenos con gris claro y zona gris claro encerrada por la línea a puntos en la figura 12). Esta actividad sísmica se localizó a lo largo de la falla Picagres y primordialmente dentro de la zona transtensiva de Charcón, tanto de su traza de falla este como en el ramal de falla oeste, el cual se localiza parcialmente dentro de la ciudad de Santiago de Puriscal. Entre el 16 de junio y el 27 de junio, la actividad sísmica disminuyó dentro de la depresión tectónica de Charcón, asociada con la falla Picagres y se incrementó en la falla Purires (círculos gris en Fig. 12). La actividad sísmica reportada por Güendel et al. (1990), para el período entre el 30 de junio y el 11 de julio, muestra claramente que el terremoto de Barbacoas del 30 de junio de 1990 (M 5,1) y su secuencia de réplicas, ocurrió en la falla Purires (círculos negros en Fig. 12). La longitud de la ruptura, de acuerdo con la ubicación del evento principal y sus réplicas, fue de unos $9 \mathrm{~km}$, aunque este valor incluye la expansión de la zona de réplicas ocurrida entre los días 30 de junio al 11 de julio (Fig. 12). La localización del evento principal realizada por Güendel et al. (1990), muestra un epicentro ubicado hacia el sector norte de la zona de ruptura, por lo que se puede considerar que la falla rompió principalmente hacia el sur. Durante el período de la sismicidad analizado por Güendel et al. (1990), no se puede definir con claridad si hubo actividad sísmica a lo largo de la falla Junquillo, dado que la sismicidad que se ubicó en sus sectores W y E, también se puede asociar con las fallas Purires y Picagres, respectivamente. Una explicación similar puede darse para la sismicidad que se observa

Fig. 9: A) Vista al NNW de tres escarpes de falla facetados al sur relacionados con tres colinas desplazadas (Ef1, Ef2 y Ef3; líneas a puntos blancas muestran los tres escarpes y las divisorias de dos colinas), a lo largo de la traza de falla Jaris (trazo indicado por flechas rellenas blancas), sobre la margen izquierda del río Jorco, al noroeste de San Ignacio de Acosta. B) Detalle del valle de falla de la falla Jaris en la zona de confluencia de los ríos Santa Elena, Caraigres y Tarrazú con el río Candelaria. La falla sugiere cortar varios niveles de terrazas de los ríos Caraigres y Candelaria. EF, DiD y Qd son respectivamente, escarpes de falla, una divisoria desviada (indicada por línea a puntos negra) y quebradas desviadas. Los círculos con números indican la ubicación de sitios referidos en el texto. Ubicación en figura 2. 


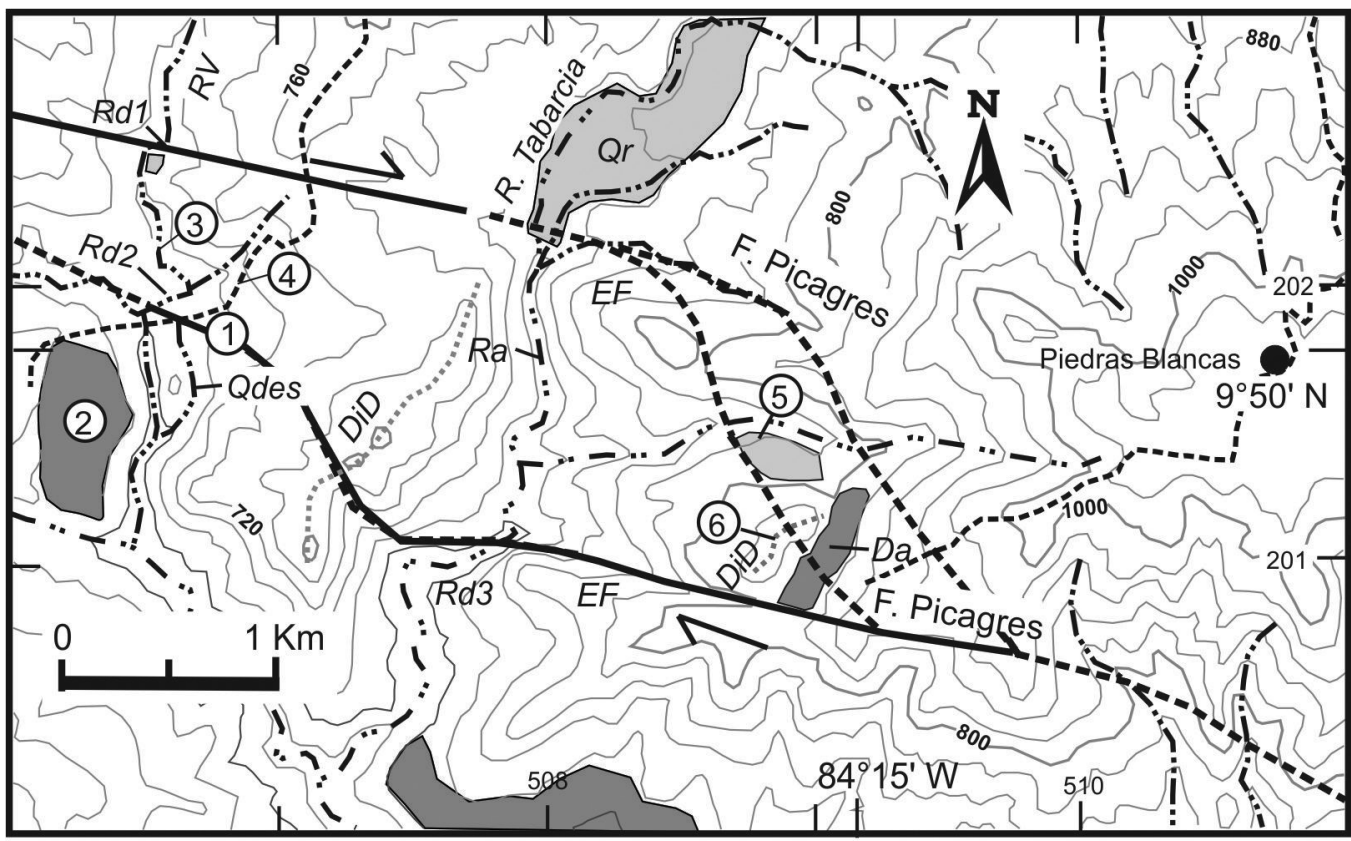

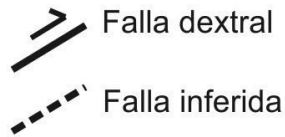

Curva de nivel cada $40 \mathrm{~m}$

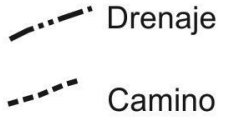

- Localidad
Depósitos aluviales Recientes

Depósitos aluviales Pleistocenos

Formaciones volcánicas Mio-PLiocenas

Fig. 10: Detalle de la neotectónica de la falla Bajos de Jorco al cruzar los ríos Viejo (RV) y Tabarcia. Ubicación en figura 2. Los círculos con números indican la ubicación de sitios referidos en el texto. Los Rd numerados son sitios mencionados en el texto, donde los ríos anteriores han sido desviados. Qdes, EF, DiD, Qr y Da indican respectivamente quebrada descabezada, escarpe de falla, divisoria desviada (línea a puntos gris), cuaternario represado y depresión anómala.

en el extremo sureste de la falla Zapote y en el extremo oeste de las fallas Jaris y Bajos de Jorco, cerca de donde terminan contra la falla Picagres.

Los datos de la RSN (UCR-ICE) para diversos períodos de tiempo del año 1990 muestran una sismicidad más dispersa que la definida por Güendel et al. (1990; Fig. 13). Para el período del 1 de abril al 15 de junio, se observa que los temblores relacionados con el enjambre ocurrieron especialmente a lo largo de la falla Picagres, y un buen número de estos en las trazas de falla que se localizan dentro de Santiago de Puriscal (círculos sin rellenar en Fig. 13). También, hay un buen número de sismos entre las fallas Picagres y Purires, los cuales no se observan en Güendel et al. (1990). Estos se puede explicar por: 1. Errores inherentes a las localizaciones; 2. Una sismicidad relacionada con la falla Junquillo o con fallas similares ubicadas en el volumen comprendido entre las fallas Purires y Picagres-Zapote, que no se expresan geomorfológicamente. Finalmente, en este período se observa un buen número de sismos localizados a lo largo de la falla Jaris, en su sector oeste y una sismicidad menor asociable con la falla Bajos 


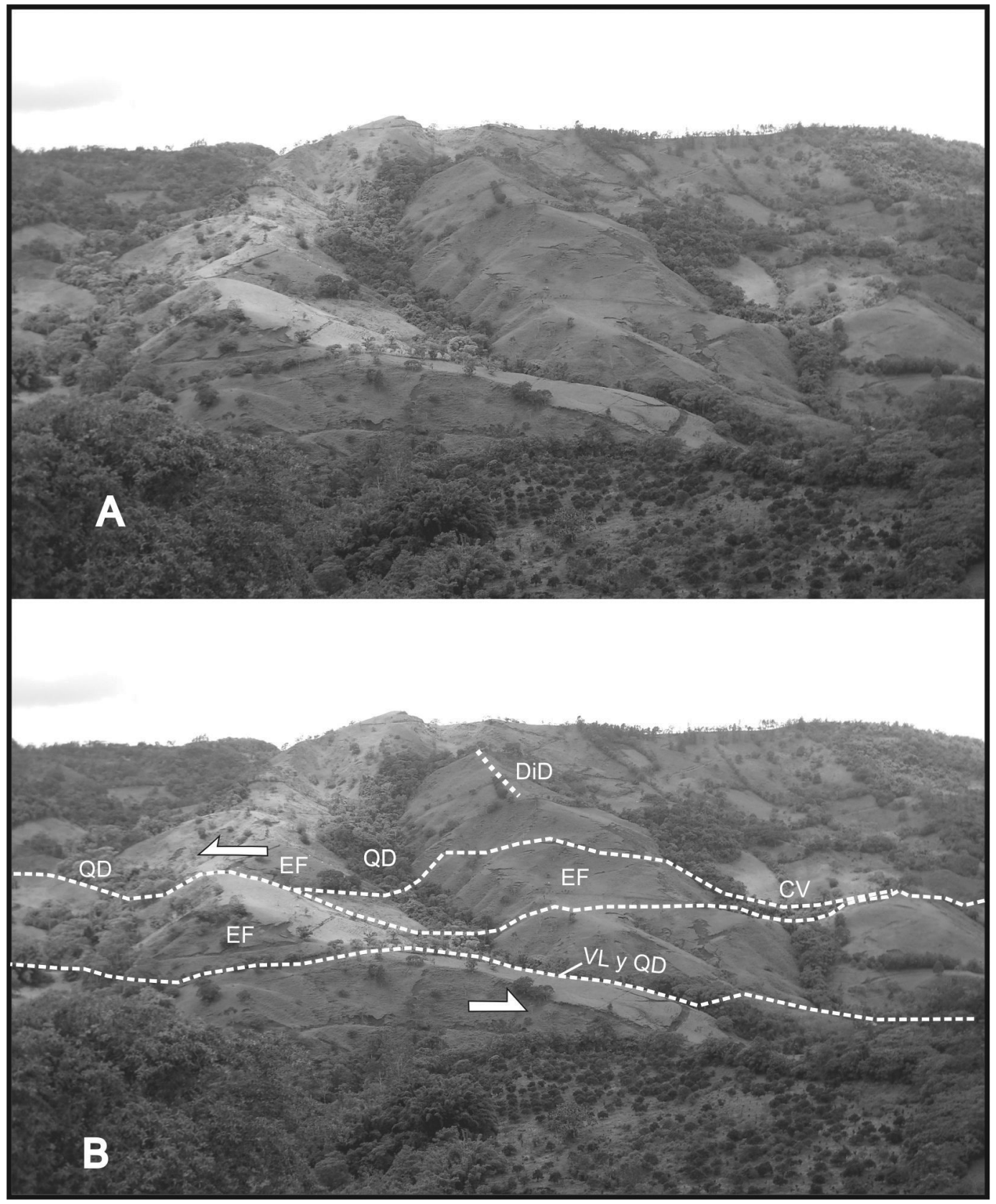

Fig. 11: A) Vista al S de la falla sinestral Junquillo, en la margen izquierda del río San José (ubicación 6 en Fig. 3). B) Interpretación de la foto mostrada en A. Se observan escarpes de falla (EF) caracterizados por facetas triangulares facetadas al N, estructura en copa de vino (CV), desvíos izquierdos de quebradas (QD), valle lineales (VL) y divisoria desviada (DiD). Las flechas rellenas en blanco muestran el movimiento horizontal relativo. 


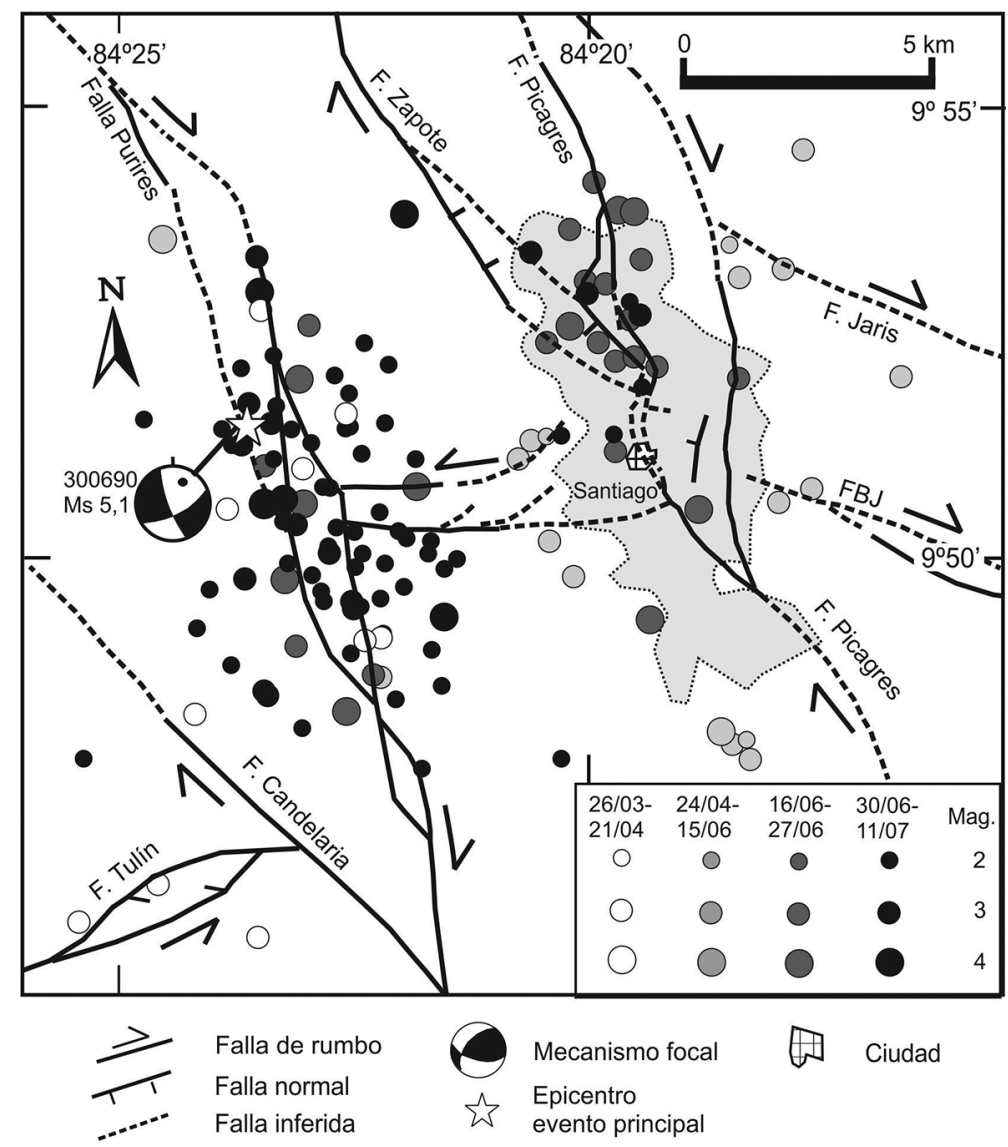

Fig. 12: Muestra la relación entre las fallas Purires y Picagres con la actividad sísmica reportada por Güendel et al. (1990), para cuatro ventanas temporales definidas entre el 26 de marzo y el 11 de julio de 1990. La estrella blanca muestra la ubicación del evento principal del terremoto de Barbacoas del 30 de junio de 1990 ( M 5,1) y el respectivo mecanismo focal obtenidos por Güendel et al. (1990). La zona elipsoidal a puntos negros y rellena en gris claro circunscribe la actividad sísmica tipo enjambre que ocurrió en el período del 24 de abril al 16 de junio en la falla Picagres. FBJ es la falla Bajos de Jorco. Ubicación en figura 2.

de Jorco. La sismicidad ocurrida entre el 16 de junio y el 15 de junio se muestra muy dispersa (círculos gris en Fig. 13), aunque el evento principal del 30 de junio de 1990 (M 5,1) se localizó muy cerca de la falla Purires, y su epicentro es similar al de Güendel et al. (1990). La sismicidad reportada por Rojas \& Barquero (1991) (profundidad < $15 \mathrm{~km}$ ) y por la RSN (UCR-ICE) ocurrida entre el 22 y el 30 de diciembre se muestra dispersa, con una tendencia a seguir la falla Picagres y el sector oeste de la falla Jaris (círculos negros en Fig. 13).
En Rojas \& Barquero (1991) se reporta el evento principal del 22 de diciembre a las 11:27 a.m. (hora local) $\left(\mathrm{M}_{\mathrm{s}} 5,7\right)$ y un segundo evento al minuto siguiente (11:28 a.m.), con una magnitud 5,0. Ambos se localizaron a lo largo de la falla Picagres (estrellas negras indicadas con los números 1 y 2 respectivamente en la Fig. 13). La distancia entre ambos epicentros y las réplicas ubicadas al norte y al sur (ocurridas hasta el 30 de diciembre), definen una longitud de ruptura de $11 \mathrm{~km}$, a lo largo de un tramo de rumbo N-S en la falla Picagres. 


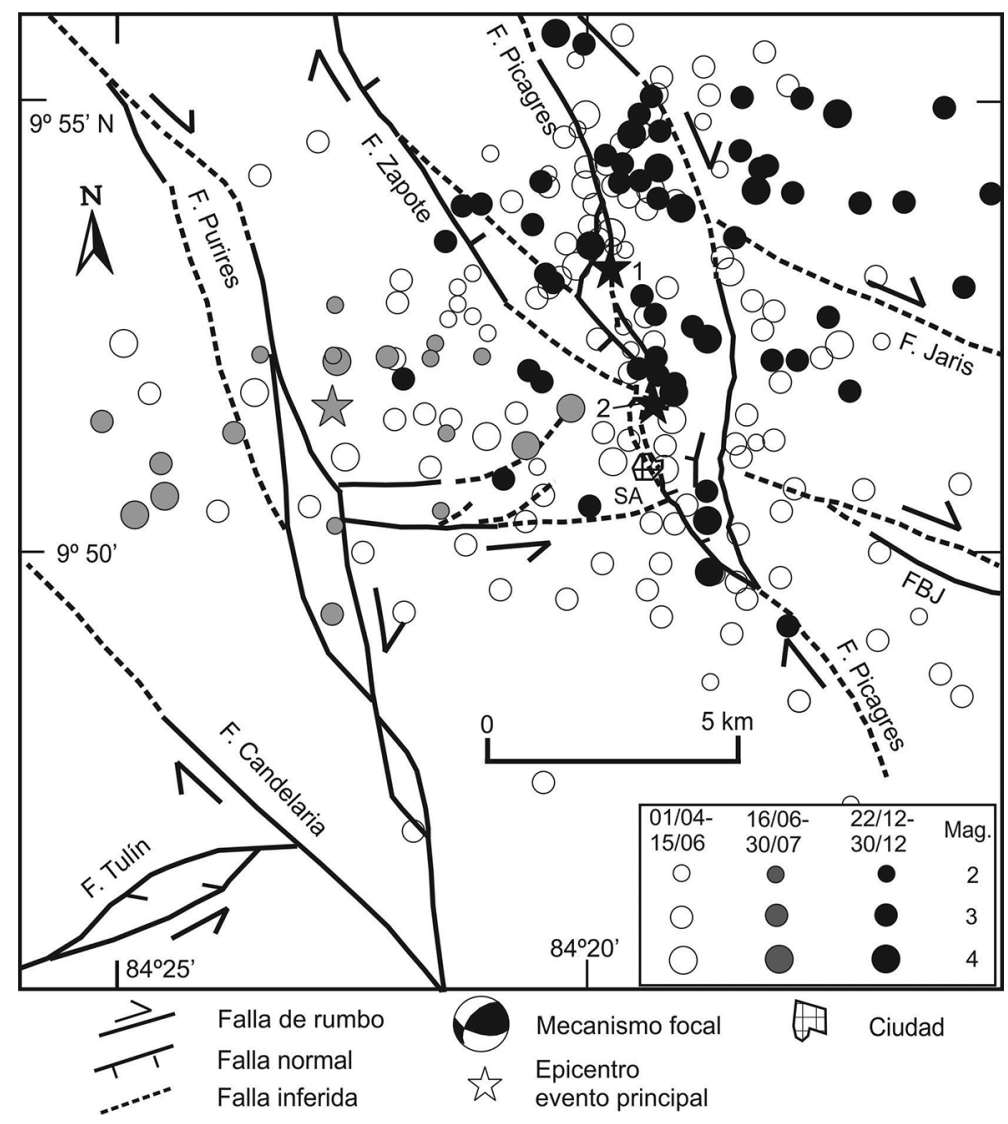

Fig. 13: Muestra la relación entre las fallas Purires y Picagres con la actividad sísmica reportada por la RSN (UCR-ICE) para diferentes períodos de 1990. La estrella gris muestra la ubicación del evento principal del terremoto de Barbacoas del 30 de junio de $1990\left(M_{s}\right.$ 5,1). Las estrellas negras numeradas con el 1 y el 2 indican respectivamente, las localizaciones del evento principal del terremoto del 22 de diciembre de 1990 ( M 5,7) y de una réplica ocurrida un minuto después. FBJ es la falla Bajos de Jorco y SA es Santiago de Puriscal. Ubicación en figura 2.

\section{Sismotectónica y rupturas de falla}

El primer estudio sismotectónico realizado en la zona de estudio fue el de Montero \& Morales (1984). Estos autores obtuvieron mecanismos focales compuestos a partir de temblores localizados a lo largo de la falla Jaris y del lado este de la misma, con planos nodales de rumbo noroeste y movimiento predominante dextral y de rumbo ENE y movimiento sinestral. Asimismo, obtuvieron un mecanismo focal con un plano nodal NW, oblicuo normal-dextral, para una zona sísmica ubicada del lado noreste de Santiago de Puriscal, donde se ha reconocido la zona transtensiva de Charcón, asociada con la falla Picagres.

Mecanismos focales para la secuencia sísmica de Puriscal de 1990, fueron reportados por Montero et al. (1990; 1991a; 1991b), Fernández (1995), Fernández \& Pacheco (1998) y Güendel et al. (1990), para los eventos de mayor magnitud del enjambre de mayo-junio. Las soluciones obtenidas por Montero et al. (1990; 1991a y b) muestran planos nodales de rumbo NW y movimiento predominantemente dextral, con componentes normales e 
inversas (Fig. 14). Los eventos y sus mecanismos concuerdan claramente con la geometría y el tipo de desplazamiento de las fallas dextrales Purires y Picagres. Asimismo, algunos sismos y sus mecanismos se pueden asociar con la falla dextral Zapote y la sinestral Junquillo (Fig. 14). Fernández (1995) y Fernández \& Pacheco (1998) determinan tres tipos de soluciones para varios sismos del enjambre: 1. De falla transcurrente, donde el plano nodal NW es dextral, 2. Inversos puros con planos nodales cercanos al E-W y 3. Normales puros de rumbo NW. Los dos últimos tipos de mecanismos no concuerdan con las fallas determinadas en este estudio. Por otro lado, las soluciones de Güendel et al. (1990) son similares con las de Montero et al. (1990; 1991a; 1991b).

Con respecto a la solución focal del temblor del 30 de junio $\left(M_{s} 5,2\right)$ reportada por Montero et al. (1990; 1991a; 1991b), la misma es consistente con su ocurrencia a lo largo del tramo donde la falla Purires tiene rumbo $\mathrm{N} 20^{\circ}-25^{\circ} \mathrm{W}$, dado que el plano nodal dextral es de rumbo similar $\left(\mathrm{N} 37^{\circ} \mathrm{W}\right.$ en Fig. 14). Obsérvese que este mecanismo tiene componente inversa. Por otro lado, la solución del Catálogo Global CMT coincide claramente con el rumbo de la falla Purires $\left(\mathrm{N} 19^{\circ} \mathrm{W}\right.$, Fig. 14) y tiene componente normal, lo cual concuerda con el tipo de desplazamiento determinado para la fa1la Purires, en el sector donde ocurrió la ruptura de falla. La solución de Fernández (1995) y Fernández \& Pacheco (1998) es de falla normal con planos nodales NW, lo cual no corresponde con el desplazamiento determinado para la falla Purires, ni con los mecanismos determinados por otros autores referidos previamente. La solución focal de Güendel et al. (1990), tiene un plano nodal NNW y movimiento dextral con componente normal, lo cual concuerda bastante bien con las características geométricas y de desplazamiento determinadas para la falla Purires en este estudio (Fig. 12).

Sugerencia de ruptura en superficie fue reportada por Montero et al. (1990; 1991a) para los eventos del enjambre ocurridos entre el 7 de junio y 8 de junio de 1990, entre los que destacan los eventos del 7 de junio $\left(M_{d} 4,8\right)$ a las 18:31 (hora local; 8 de junio, 00:31 GMT) y el del 8 de junio $\left(\mathrm{M}_{\mathrm{d}} 4,8\right)$ a las 18:34 (hora local; 9 de junio, 00:34
GMT) (ver lista de sismos reportada por Rojas $\&$ Barquero, 1991). Estos sismos originaron una ruptura en superficie de unos 400 metros de longitud y de rumbo $\mathrm{N} 12^{\circ} \mathrm{W}$, que cortó en forma continua varias propiedades, con construcciones y suelos firmes, originando desvíos horizontales derechos, que tuvieron magnitudes entre $2 \mathrm{~cm}$ y $0,4 \mathrm{~cm}$ y un desplazamiento vertical, donde el lado este bajo $10 \mathrm{~cm}$ (Fig. 15; ver detalles de las evidencias de la ruptura superficial en Montero et al., 1990, y en Montero et al., 1991a). La ruptura en superficie determinada es concordante con el trazo de la falla Picagres al pasar por la localidad de San Antonio, y que limita el borde este de la zona de transtensión de Charcón (Figs. 5 y 15A). Este reporte de Montero et al. (1990) y Montero et al. (1991a) fue la primera evidencia de ruptura en superficie asociada con sismos en Costa Rica, y es anómala porque se relaciona con temblores de relativa baja magnitud. La explicación es que estos sismos del 7 y 8 de junio tuvieron una profundidad muy superficial, que pudo haber sido incluso menor a $1 \mathrm{~km}$. Yeats et al. (1997) realizan una recopilación de terremotos históricos con rupturas de falla superficial. El cuadro mostrado incluye desplazamientos y longitudes de ruptura similares a los reportados en este estudio, tanto para sismos con magnitudes parecidas a los del 7 y 8 de junio de 1990, así como con magnitudes entre 5,0 y 6,0. Los anteriores estudios fueron reportados por diversos autores en revistas de prestigio internacional.

Evidencia de ruptura en superficie no fue reportada para el sismo del 30 de junio de $1990\left(\mathrm{M}_{\mathrm{s}}\right.$ 5,$\left.1 ; \mathrm{M}_{\mathrm{w}} 5,5\right)$, aunque el trabajo de campo, que se realizó inmediatamente después del sismo, solo cubrió parcialmente la región donde se localiza la traza de la falla Purires. Sin embargo, dada la baja magnitud de este sismo, es poco probable que el mismo hubiera generado una ruptura de falla en superficie. La recopilación de la información macrosísmica realizada para este sismo revela que las intensidades máximas Mercalli Modificada (MM) alcanzaron el valor de VII grados (Barquero et al., 1991b; Fig. 14), dentro de una zona que incluye totalmente la ruptura de falla definida en este estudio a partir de los datos de sismicidad de Güendel et al. (1990). 


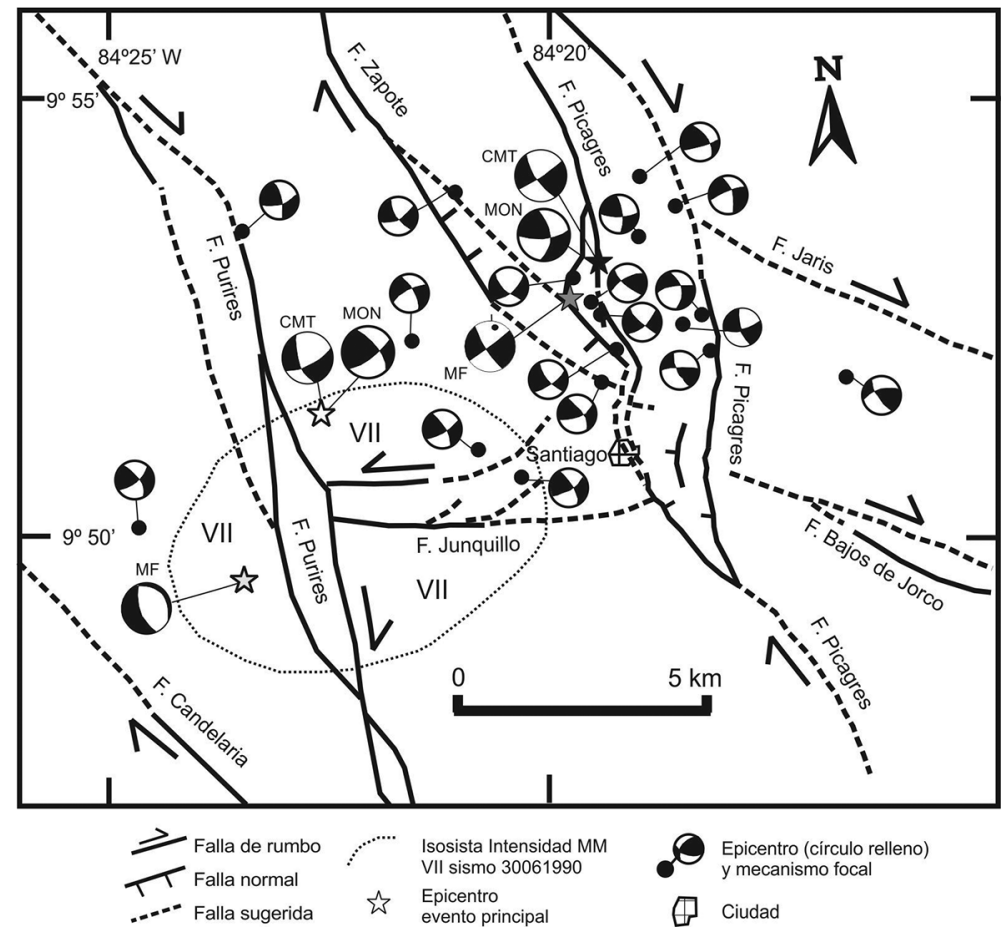

Fig. 14: Relación entre la sismotectónica y las fallas Picagres, Purires, Zapote, Jaris y Junquillo. Los epicentros y mecanismos focales fueron tomados de Montero et al. (1990; 1991a, 1991b) y del Catálogo Global del Centroide del Tensor del Momento Sísmico (solución CMT). La estrella blanca es el epicentro del evento principal del terremoto de Barbacoas del 30 de junio de 1990 ( M $\left._{\mathrm{s}} 5,1\right)$ reportado por la RSN (UCR-ICE) y las soluciones focales de Montero et al. (1990; 1991a; 1991b; MON) y de CMT. La estrella gris claro es el epicentro del anterior terremoto reportado por Fernández (1995) y Fernández \& Pacheco (1998), con su respectivo mecanismo focal (indicado como MF). La estrella gris es el epicentro del terremoto del 22 de diciembre de 1990 ( $\left.\mathrm{M}_{\mathrm{s}} 5,7\right)$ reportado por Fernández (1995) y Fernández \& Pacheco (1998), con su respectivo mecanismo focal (indicado como MF). La estrella negra es el epicentro del anterior sismo obtenido por Montero et al. (1991a; 1991b) y la respectiva solución focal (indicada por MON). También, se muestra la solución CMT para este último terremoto.

Con respecto a la localización epicentral y el mecanismo focal del terremoto de Piedras Negras del 22 de diciembre de 1990 (M 5,7), existen varias soluciones (Montero et al., 1991a y 1991b; Fernández, 1995; Fernández \& Pacheco, 1998; Catálogo Global CMT; Fig. 14). Montero et al. (1991a y 1991b) originalmente propusieron un epicentro que se localizaba a lo largo de la traza este de falla Picagres. Sin embargo, una nueva relocalización de este evento por parte de la RSN (UCR-ICE), ha determinado un epicentro localizado directamente sobre el ramal oeste de la falla Picagres (Figs. 13 y 14), al igual que la localización de un evento de magnitud local 5,1, reportado por Rojas \& Barquero (1991). El plano nodal dextral del mecanismo focal de Montero et al. (1991a y 1991b) tiene un rumbo cercano al N-S y coincide con el rumbo que tiene la falla Picagres en su sector central-norte. Por lo tanto, se interpreta que el epicentro y el mecanismo focal de estos autores implican una ruptura del tramo de rumbo nortesur del ramal oeste de la falla Picagres, como consecuencia del terremoto de Piedras Negras del 22 de diciembre de 1990 (M 5,7). Por otro lado, la localización epicentral de Fernández (1995) y de Fernández \& Pacheco (1998) se localiza en el tramo de la falla Picagres, que es sub-paralelo al río Picagres. Igualmente, las soluciones focales de Fernández (1995), Fernández \& Pacheco (1998) y del Catálogo Global CMT, tienen el plano nodal de componente dextral con un rumbo similar al de la falla Picagres, en el tramo sub-paralelo al río 


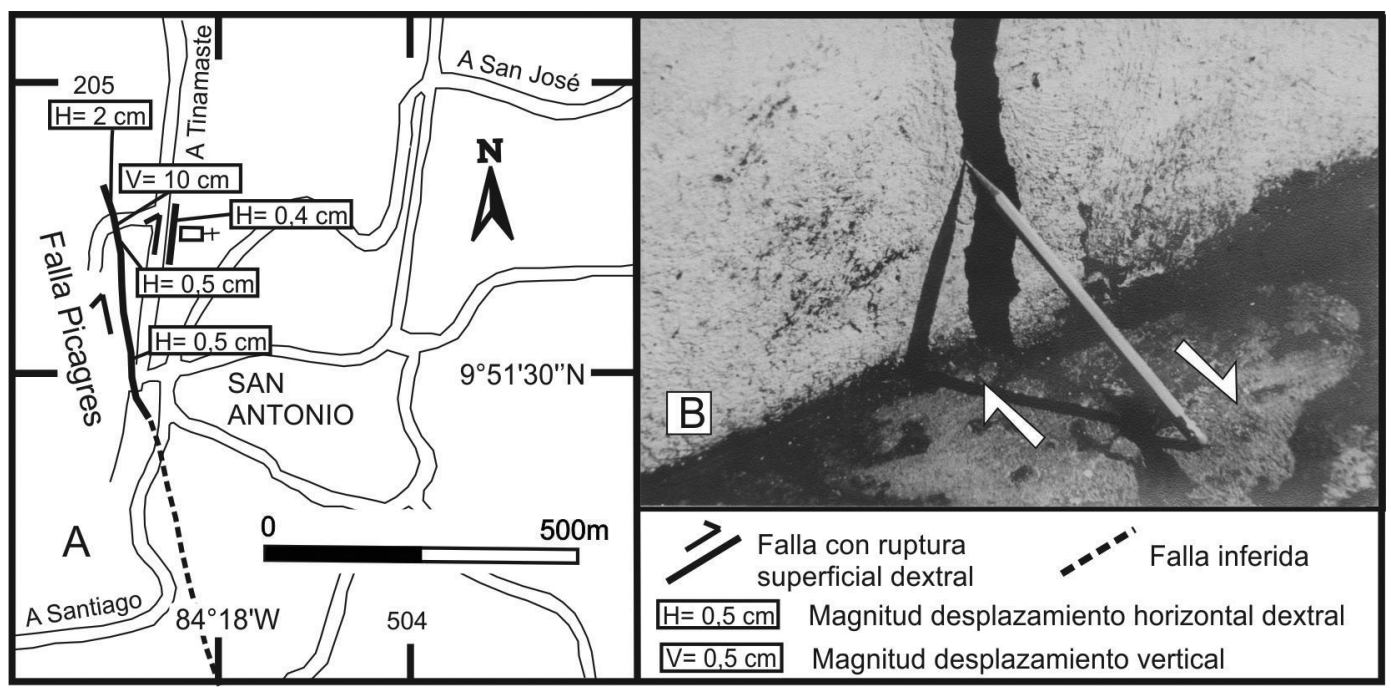

Fig. 15: A) Muestra la ruptura de falla superficial de $400 \mathrm{~m}$ de longitud, rumbo $\mathrm{N} 12^{\circ} \mathrm{W}$ y los desplazamientos horizontales y verticales (en cm) observados en diversas obras civiles, a raíz de los sismos ocurridos entre el 7 y el 8 de junio de 1990. La ruptura se asocia con el ramal este de la falla Picagres y de la estructura transtensiva de Charcón. Ubicación en figura 5. B) Muestra el desplazamiento lateral derecho de $2 \mathrm{~cm}$, observado en una pared de una casa en el sector norte de la ruptura de falla. La punta y el borrador del lápiz, que miden cerca de $2 \mathrm{~cm}$, sirven de escala para indicar un desplazamiento horizontal derecho de $2 \mathrm{~cm}$ en este sitio.

Picagres (Fig. 14). Lo anterior sugiere una ruptura con una orientación más al noroeste de lo que indican los datos de Montero et al. (1991a; 1991b) y con lo que interpretamos en este estudio.

Con respecto a una ruptura de falla en superficie asociada con el terremoto de Piedras Negras del 22 de diciembre (M 5,7), Montero et al. (1991a y $\mathrm{b}, \mathrm{y}$ notas de campo adicionales) reportan que durante una visita al área epicentral del terremoto, realizada el día 29 de diciembre de 1990, en el sitio 11 (Fig. 5), se observó una fractura sin salto y abierta, transversal al camino y de rumbo $\mathrm{N} 07^{\circ} \mathrm{E}$, que se divide en dos fracturas de rumbos $\mathrm{N} 07^{\circ} \mathrm{W}$ y $\mathrm{N} 18^{\circ} \mathrm{E}$. Un poco más al sur, en el sitio 12 se observó una grieta de rumbo $\mathrm{N} 87^{\circ} \mathrm{E}$ cortando la calle. Finalmente, en el tramo del camino entre Piedras Negras y Desamparaditos enmarcado con el número 13 (Fig. 5), se observó una zona llena de fracturas de unos 300 metros de largo y con rumbos oscilantes entre NW y ENE, que terminaba unos 150 metros antes de llegar al río Chile. En esta zona se midieron los rumbos de 33 fracturas, una de las cuales se determinó era una falla que buzaba $53^{\circ}$ al $\mathrm{N} 44^{\circ} \mathrm{W}$ y tenía estrías con $30^{\circ}$ al NNE (ver recuadro en Fig. 5). Veinte fracturas con rumbos al NW cortaban el camino y son más relacionables con una zona de falla, mientras que trece que eran sub-paralelas con el camino, pueden relacionarse con hundimientos en los bordes del mismo. Los tres sitios anteriores se localizan muy cerca o parcialmente dentro de donde se ubica la traza de falla Picagres. Estos datos sugieren que no es posible descartar que el terremoto haya originado una ruptura de falla en superficie, ya sea primaria, por lo menos en un trecho de la misma, o asociada con una falla secundaria (Yeats et al., 1997). Sin embargo, la relativa baja magnitud del terremoto $\left(\mathrm{M}_{\mathrm{s}}\right.$ 5,$\left.7 ; \mathrm{M}_{\mathrm{w}} 5,9\right)$, hace poco probable que este hubiera generado una ruptura de falla superficial cosísmica y continua a lo largo de todo el trecho N-S que se rompió, el cual se estima en $11 \mathrm{~km}$. Esto es, entre el borde sur de la zona de tracción de Charcón y hasta cerca de la localidad de Piedras Negras. A lo largo de esta zona se ubicaron los deslizamientos más volumétricos asociados con el terremoto y ocurrieron importantes daños a las construcciones (Rojas \& Barquero, 1991; Montero et al., 1991a y b y notas de campo adicionales). 


\section{DISCUSIÓN Y CONCLUSIONES}

Se ha definido con base en evidencias morfotectónicas, estructurales y sismológicas las fallas dextrales Purires (como un ramal de la falla Candelaria), Picagres y Jaris, con rumbos predominantes entre NW a N-S, como el principal sistema de fallas activas de la zona de estudio (Fig. 2). La falla Jaris tiene unos $45 \mathrm{~km}$ de longitud, se extiende al SE desde San Pablo de León Cortés, en las estribaciones noroeste de la cordillera de Talamanca, hasta cerca de la localidad de Piedras Negras al NW. Esta falla incluye una zona transtensiva en el sector que se localiza cerca de las localidades de Palmichal y Corrolar. Asimismo, la falla Jaris incluye la zona transpresiva de Dragón en su sector sureste. Por otro lado, la falla Picagres, se extiende unos $18 \mathrm{~km}$, al sur desde el río Jorco y se continúa al norte del río Virilla, fuera de la zona de estudio. Incluye la zona transtensiva de Charcón, cuyo ramal oeste se localiza parcialmente dentro de la ciudad de Santiago de Puriscal, donde tiene rumbo N-S. Con respecto a la falla Purires, se determinó que tiene una longitud cercana a los $25 \mathrm{~km}$ y es un ramal NNW de la falla Candelaria. Se extiende al sur, desde cerca de la confluencia de los ríos Quivel y Grande de Candelaria, mientras que hacia el norte, cruza el río Tárcoles, donde se continúa dentro de los Montes del Aguacate.

Las fallas Bajos de Jorco y Zapote, también de rumbo noroeste y movimiento predominante dextral, se consideran como posiblemente activas. La falla Zapote tiene dos ramales siendo el más largo de unos $12 \mathrm{~km}$ dentro de la zona de estudio, iniciando al sur cerca de Santiago de Puriscal, siguiendo al noroeste cerca de la localidad de Jateo y se continúa al norte dentro de los montes del Aguacate, donde debe ser estudiada con mayor detalle. Esta falla de rumbo noroeste y movimiento dextral predominante, muestra también una componente normal en el área de estudio, donde el bloque E baja. La falla Zapote es un ramal de la falla Picagres y entre ambas originan la zona de transtensión de Zapote. Ambas fallas se unen al norte fuera de la zona de estudio, y luego más al norte se continúa la falla con una traza simple con el nombre de falla Picagres dentro de los montes del Aguacate (Fig. 1).

La falla Bajos de Jorco, con una longitud de unos $16 \mathrm{~km}$, se inicia al sureste de Santiago de Puriscal y termina al sureste contra la falla Jaris.

Con respecto al fallamiento sinestral, se han definido varias trazas con un patrón en abanico, que constituyen la falla activa Junquillo, las cuales tienen un rumbo entre ENE a E-W y una longitud de $7 \mathrm{~km}$ para las dos trazas principales. Estas trazas de falla se encuentran comprendidas entre las fallas Purires y Picagres, y son subsidiarias al sistema de falla dextral, que caracteriza a la zona de estudio.

La evidencia sismológica y sismotectónica señala que la secuencia de temblores de Puriscal de 1990, se originó principalmente en las fallas Picagres y Purires. Actividad sísmica menor puede ser asociada con las fallas dextrales Zapote, Bajos de Jorco y Jaris y con la sinestral Junquillo. $\mathrm{La}$ actividad sísmica superficial $(<20 \mathrm{~km})$ en la zona de Puriscal fue disparada por los terremotos interplaca de la entrada del golfo de Nicoya del 25 de marzo de $1990\left(\right.$ M $_{\mathrm{s}} 7,0$ y M M $_{\mathrm{s}}$,1). Con base en la sismicidad reportada por Güendel et al. (1990), se interpreta que entre fines de marzo y mediados de abril, la actividad se localizó en la falla Purires. Entre fines de abril y mediados de junio, la actividad tipo enjambre migró a la falla Picagres, ubicándose predominantemente dentro de la zona transtensiva de Charcón, tanto en su ramal este como en el oeste, que se localiza parcialmente dentro de Santiago de Puriscal. En el ramal este, los sismos ocurridos entre el 7 y el 8 de junio originaron una ruptura de falla superficial de unos $400 \mathrm{~m}$ de longitud, un rumbo $\mathrm{N} 12^{\circ} \mathrm{W}$, y con desplazamientos dextrales entre $2 \mathrm{~cm}$ y $0,4 \mathrm{~cm}$, que corresponden con un segmento del ramal este de la falla Picagres. A partir de mediados de junio, la actividad sísmica se dividió entre las fallas Purires y Picagres. Entre el 30 de junio y el 12 de julio, la actividad se concentró en la falla Purires.

Evidencia sismológica y sismotectónica indica que la falla Purires fue la fuente sísmica del evento de Barbacoas del 30 de junio de 1990 
$\left(M_{\mathrm{s}}\right.$ 5.1). Una longitud de ruptura de unos $9 \mathrm{~km}$ puede ser definida para este evento principal y las réplicas ocurridas hasta el 11 de julio. Luego de una disminución de la actividad sísmica entre mediados de julio e inicios de diciembre, ocurrió el terremoto de Piedras Negras del 22 de diciembre de 1990 ( M 5,7), que incluyó una importante réplica de magnitud local 5,1, un minuto después del evento principal. La evidencia sismológica, sismotectónica y macrosísmica indica que el segmento que rompió durante este terremoto tiene unos $11 \mathrm{~km}$ de longitud. Esta ruptura se ubica en el sector de la falla Picagres de rumbo cercano al N-S, iniciando al sur donde cierra la estructura transtensiva de Charcón (Fig. 4) y terminando al norte de la localidad de Piedras Negras.

El estilo neotectónico de fallas predominantemente dextral determinado en este estudio, no concuerda con el propuesto por Porras et al. (2012), para una zona de estudio que es similar al sector norte del presente trabajo. Estos últimos autores sugieren una serie de fallas de cabalgamiento de rumbo NW, vergencia al SW y con una componente de rumbo sinestral. De acuerdo con los resultados obtenidos en nuestra investigación, no se encuentra evidencia morfotectónica, sismológica ni sismotectónica que sustente una tectónica como la propuesta en el estudio de Porras et al. (2012), quienes consideran que ha estado activa al menos desde el Pleistoceno Medio. Los resultados reportados en esta investigación sustentan en forma adecuada una tectónica de rumbo noroeste y de desplazamiento predominantemente dextral, en la zona central-oeste del centro del país, lo cual también es característico de otros sectores del Cinturón Deformado del Centro de Costa Rica (Montero et al., 2013).

\section{AGRADECIMIENTOS}

Esta investigación es resultado del proyecto de investigación No. 830-A8-133 "Investigación de fallas activas en áreas claves de Costa Rica", financiado por la Vicerrectoria de Investigación de la Universidad de Costa Rica. Se agradece a la Red Sismológica Nacional (RSN, UCR-ICE) por proporcionar información sismológica de su base de datos. Se agradece a un árbitro anónimo sus pertinentes observaciones que ayudaron a resolver diversas inconsistencias especialmente en la cinemática de algunas fallas. Se agradece a Elena Badilla por haber proporcionado los modelos de elevación digital del terreno, que permitieron realizar varias de las figuras del presente artículo. Asimismo, se agradece a Maikol Rojas y Andrés Ulloa, estudiantes del curso de neotectónica, con quienes se realizó un par de giras a la zona de estudio, en las cuales se tomaron datos que enriquecieron este estudio. Se agradece a Nury Morales, Willy Salazar y Javier Alvarado por su participación en varias de las giras realizadas durante esta investigación.

\section{REFERENCIAS BIBLIOGRÁFICAS}

ARIAS, O., \& DENYER, P., 1990a: Geología de la hoja Caraigres.- Escala 1: 50 000, IGN, San José.

ARIAS, O., \& DENYER, P., 1990b: Geología de la hoja Río Grande.- Escala 1: 50 000, IGN, San José.

ARIAS, O., \& DENYER, P., 1991a: Estructura geológica de la región comprendida en las hojas topográficas Abra, Caraigres, Candelaria y Río Grande, Costa Rica.Rev. Geol. Amér. Central, 12: 61-74.

ARIAS, O. \& DENYER, P., 1991b: Aspectos neotectónicos y geológicos de Puriscal y alrededores, Costa Rica.- Rev. Geol. Amér. Central, 12: 83-95.

BARQUERO, R., MONTERO, W. \& ROJAS, W., 1991a: Actividad sísmica relacionada con el sismo de Cóbano.- En BARQUERO, R. \& BOSCHINI, I. (eds): La Crisis Sísmica del Golfo de Nicoya y eventos sísmicos relacionados Costa Rica, 1990.- Dirección de Ingeniería Civil, Departamento de Geología, ICE, 45-73. 
BARQUERO, R., ROJAS, W. \& FERNÁNDEZ, M., 1991b: El enjambre de Puriscal y Mora de 1990.- En BARQUERO, R. \& BOSCHINI, I. (eds): La Crisis Sísmica del Golfo de Nicoya y eventos sísmicos relacionados, Costa Rica, 1990.- Dirección de Ingeniería Civil, Departamento de Geología, ICE, 74-94.

BILEK, S., ELLIOT, C. \& BERTELLONI, C., 2009: Triggered seismicity associated with the 1990 Nicoya, Costa Rica, $M_{w} 7.0$ earthquake.- Geochem. Geophys. Geosyst. 10, DOI: 10.1029/2008GC002317.

CASTILlO, R., 1969: Geología de los Mapas Básicos Abra y una parte de Río Grande, Costa Rica.- Informe MEIC, 40 págs. + mapa 1: 50000 .

DENYER, P. \& ARIAS, O., 1990a: Geología de la hoja Abra.- Escala 1: 50 000, IGN, San José.

DENYER, P. \& ARIAS, O., 1990b: Geología de la hoja Candelaria.- Escala 1: 50 000, IGN, San José.

DENYER, P. \& ARIAS, O., 1991: Estratigrafía de la región central de Costa Rica.- Rev. Geol. Amér. Central, 12: 1-59.

DENYER, P. \& MONTERO, W., 1988: Mapa geoestructural y de sismos del Valle Central.- Escala 1: 150 000, IGN, San José.

DÓNDOLI, C. \& CHAVES, R., 1968: Mapa adjunto al estudio geológico del Valle Central.- Escala 1: 150 000, IGN, San José.

FENG, L., NEWMAN, A. V., PROTTI, M., GONZÁLEZ, V., JIANG, Y., \& DIXON, T. H., 2012: Active deformation near the Nicoya Peninsula, northwestern Costa Rica, between 1996 and 2010: Interseismic megathrust coupling.- J. Geophys. Res. 117, DOI: 10.1029/2012JB009230.
FERNÁNDEZ, M., 1995: Análisis sísmico en la parte central de Costa Rica y evaluación del hipotético sistema de falla transcurrente de Costa Rica.- 85 págs. + apéndices. Univ. Nac. Autónoma de México, México D. F. [Tesis M.Sc.].

FERNÁNDEZ, M \& PACHECO, J., 1998: Sismotectónica de la región central de Costa Rica.- Rev. Geol. Amér. Central, 21: 5-23.

GÜENDEL, F., PROTTI, M., SIMILA, G. \& MCNALLY, K., 1995: Recent seismicity in Costa Rica and relation to regional tectonics.- AGU Fall Meeting: F429.

GLOBAL CMT CATALOG SEARCH, s.f..http://www.globalcmt.org. [Consulta: 1 de julio de 2010].

GÜENDEL, F., SEGURA, J., MONTERO, C., GONZALEZ, V., ROJAS, D., BRENES, J., MATA, A., BARQUERO, J., BARRANTES, O., BARBOZA, V., FERNÁNDEZ, E., RODRIGUEZ, H., SAENZ, R., DUARTE, E., \& MARINO, T., 1990: Informe Preliminar Secuencia Sísmica de Puriscal 26 de Marzo - 11 de Julio 1990.- 21 págs. +12 figuras +4 apéndices. OVSICORI-UNA, Heredia.

LAFEMINA, P., DIXON, T.H., GOVERS, R., NORABUENA, E., TURNER, H., SABALLOS, A., MATTIOLI, G., PROTTI, M., \& STRAUCH, W., 2009: Fore-arc motion and Cocos Ridge collision in Central America.- Geochem. Geophys. Geosyst. 10(1), DOI: 10.1029/2008GC002181.

LEWIS, J.C., BOOZER, A.C., LÓPEZ, A., \& MONTERO, W., 2008: Collision versus sliver transport in the hanging wall at the Middle America subduction zone: Constraints from background seismicity in central Rica.- Geochem. Geophys. Geosyst. 9, DOI: 10.1029/2007GC001711. 
LÓPEZ, A., 1999: Neo-and paleostress partitioning in the SW corner of the Caribbean plate and its fault reactivation potential.294 págs. Univ. de Tubingen, Alemania [Tesis Ph.D].

LÓPEZ, A., 2012: Andersonian and Coulomb stresses in Central Costa Rica and its fault slip tendency potential: new insights into their associated seismic hazard.- Geol. Soc. London, Spec. Publ., 367, DOI: 10.1144/ SP367.3.

MCCLAY, K. \& DOOLEY, T., 1995: Analogue models of pull-apart basins.- Geology, 23: 711-714.

MACMILLAN, I., GANS, P. B., \& ALVARADO, G., 2004: Middle Miocene to present plate tectonic history of the southern Central American Volcanic Arc.- Tectonophysics, 392: 325-348.

MARSHALL, J. S., FISHER, D. M., \& GARDNER, T. W., 2000: Central Costa Rica deformed belt: Kinematics of diffuse faulting across the western Panama block.Tectonics, 19: 468-492.

MARSHALL, J., IDLEMAN, B., GARDNER, T., \& FISHER, D., 2003: Landscape evolution within a retreating volcanic arc, Costa Rica, Central America.- Geology, 31: 419422.

MONTERO, W., 1994: Neotectonics and related stress distribution in a subduction-collisional zone: Costa Rica.- En: SEYFRIED, H. \& HELLMANN, W. (eds): Geology of an evolving island arc, The Istmus of Southern Nicaragua, Costa Rica and Western Panamá.- Profil, 7: 125-141.

MONTERO, W., 2001: El Cinturón Deformado del Centro de Costa Rica: Frontera oeste de la microplaca de Panamá.- Rev. Geol. Amér. Central, 24: 29-56.
MONTERO, W., BARAHONA, M., ROJAS, W. \& TAYLOR, M., 2005: Los sistemas de falla Agua Caliente y Río Azul y relevos compresivos asociados, valle Central de Costa Rica.- Rev. Geol. Amér. Central, 33: 7-27.

MONTERO, W., BOSCHINI, I. \& ROJAS, W., 1991a: Interpretación neotectónica.- En BARQUERO, R. \& BOSCHINI, I. (eds): La Crisis Sísmica del Golfo de Nicoya y eventos sísmicos relacionados, Costa Rica, 1990.- Dirección de Ingeniería Civil, Departamento de Geología, ICE, 114-134.

MONTERO, W., LEWIS, J., MARSHALL, J., KRUSE, S. \& WETMORE, P., 2013: Neotectonic faulting and fore arc sliver motion along the Atirro-Río Sucio fault system, Costa Rica, Central America.Geol. Soc. Amer. Bull. 125(5-6): 857-876, DOI: 10.1130/B3047.1.

MONTERO, W. \& MORALES, L. D., 1984: Sismotectónica y niveles de actividad de microtemblores en el suroeste del Valle Central, Costa Rica.- Rev. Geofísica, 21: 21-41.

MONTERO, W., ROJAS, W., BOSCHINI, I. \& BARQUERO, R., 1990: Neotectónica de la región de Puriscal. Origen del enjambre de mayo-julio de 1990.- 13 págs. + figuras + fotos + mapa 1: 50 000. RSN-ICE-UCR.

MONTERO, W., ROJAS, W., BOSCHINI, I., BARQUERO, R. \& FLORES, H., 1991b: Neotectónica de la región de Puriscal. Origen de la sismicidad de mayo-diciembre de 1990.Mem. V Sem. Nac. Geotecnia - I ${ }^{\text {er }}$ Encuentro Centroamer. Geotecnistas. 4.38-4.51.

MORELL, K.D., KIRBY, E., FISHER, D.M. \& VAN SOEST, M., 2012: Geomorphic and exhumational response of the Central American Volcanic Arc to Cocos Ridge subduction.- J. Geophys. Res. 117, DOI: 10.1029/2011JB008969. 
PORRAS, H., CASCANTE, M., GRANADOS, R. \& ALVARADO, G., 2012: Volcanoestratigrafía y tectónica del Valle Central Occidental y las estribaciones de los Montes del Aguacate a lo largo de la ruta 27, Costa Rica.- Rev. Geol. Amér. Central, 47: 69-93.

ROJAS, W. \& BARQUERO, R., 1991: El temblor de Piedras Negras, 22 de diciembre de 1990.- En BARQUERO, R. \& BOSCHINI, I. (eds): La Crisis Sísmica del Golfo de
Nicoya y eventos sísmicos relacionados, Costa Rica, 1990.- Dirección de Ingeniería Civil, Departamento de Geología, ICE, 94104.

QUINTERO, R. \& GÜENDEL, F., 2000: Stress field in Costa Rica.- J. Seismol. 4: 297319.

YEATS, R.S., SIEH, K. \& ALLEN, C.R., 1997: The geology of earthquakes.- 568 págs. Ed. Oxford University Press, Oxford. 
